\title{
Cloning and differential expression of estrogen receptor and aromatase genes in the self-fertilizing hermaphrodite and male mangrove rivulus, Kryptolebias marmoratus
}

\author{
Edward F Orlando ${ }^{1,2}$, Yoshinao Katsu ${ }^{2}$, Shinichi Miyagawa ${ }^{2}$ and Taisen Iguchi ${ }^{2}$ \\ ${ }^{1}$ Department of Biological Sciences, Florida Atlantic University, 5600 US 1, North, Ft. Pierce, Florida 34946, USA \\ ${ }^{2}$ Department of Bioenvironmental Research, Okazaki Institute for Integrative Bioscience, National Institutes of Natural Science, 5-1 Higashiyama, Myodaiji, Okazaki, Aichi 444-8787, \\ Japan \\ (Requests for offprints should be addressed to E F Orlando; Email: eorlando@ fau.edu)
}

\begin{abstract}
The mechanisms underlying sex determination and differentiation in fishes are labile in response to environmental parameters. Sex-specific phenotypes are largely regulated by sex steroids, and the inhibition or the stimulation of aromatase can reverse sex as well as alter secondary sexual characteristics in fishes. Among vertebrates, the mangrove rivulus is the only known self-fertilizing hermaphrodite. Throughout most of its range, rivulus appear to exist as clonally reproducing hermaphrodites. However, outcrossing has been documented in Belize, where up to $25 \%$ of rivulus collected are males. The direct development of (primary) males occurs when embryos are incubated at $18{ }^{\circ} \mathrm{C}$ and hermaphrodites develop into secondary males when held at $28^{\circ} \mathrm{C}$. Given the importance of sex steroids, their receptors, and aromatase in sex determination and differentiation of fishes, we cloned, sequenced, and quantified the expression of estrogen receptors $(E R \alpha, E R \beta)$ and ovarian $(A r o A)$ and brain $(A r o B)$ aromatase genes. Hermaphrodites had increased $E R \alpha, E R \beta$, $A r o A$, and $A r o B$ gene expression in the liver, gonad, gonad, and brain respectively, compared to males. These data are consistent with the gene expression data reported for other species and are reflective of the presence of ovarian tissue in the hermaphrodites. Interestingly, we show the elevated expression of brain aromatase in the hermaphrodite brain. The role of the dimorphic expression of brain aromatase in the regulation of sex-specific characteristics is intriguing and requires further research. Because of the uniqueness of its reproductive biology, rivulus is an excellent model for elucidating the mechanisms regulating vertebrate sex determination and sexual differentiation.
\end{abstract}

Journal of Molecular Endocrinology (2006) 37, 353-365

\section{Introduction}

\section{Sex determination and sexual differentiation}

Determination of female or male phenotype in mammals is under strict genetic control, which directs the development of ovaries or testes (Graves 1994). Differentiation of sexually dimorphic characteristics occurs mostly under the control of the sex steroid hormones, androgens and estrogens, which are synthesized primarily in the gonad (Wilson 1994).

Like mammals, most fish species have separate sexes (called gonochorism) and believed to have genetic sex determination. In contrast to mammals, the mechanisms underlying sex determination and differentiation in fishes vary widely and are labile in response to environmental parameters, including temperature and demographic structure of the local population (Devlin \& Nagahama 2002). Furthermore, sex can be purposely manipulated via treatment with synthetic chemicals, a common practice in aquaculture (Donaldson 1996). Both sex determination and sexual differentiation are altered in fishes exposed to endocrine disrupting chemicals (Damstra et al. 2002, Nagahama et al. 2004). A naturally occurring example of lability in sex determination and sexual differentiation is that of hermaphroditic fishes. Hermaphrodites either contain both ovarian and testicular tissues (called simultaneous hermaphroditism) or develop first as one sex and then change to the other (called sequential hermaphroditism) (Shapiro 1994).

Compared to sexual differentiation, little is known about the genetic and the molecular mechanisms that control sex determination in fishes and why genetic sex determination is relatively easier to override by environmental factors compared with mammals. Arguably, the best studied model of sex determination in fishes is the medaka, Oryzias latipes, in which the first sex determining gene, DNA motif on the Y chromosome $(D M Y)$, in a non-mammalian vertebrate has been identified (Matsuda et al. 2002). Analogous to the SRY gene in mammals, $D M Y$ expression has been documented in the Sertoli cells of the XY gonad during the time of sex determination. Two other genes, DMRT-1b(Y) 
and the vasa homologs (primary germ cell markers) vas-s and vas, have also been associated with early events during sex determination of medaka and tilapia (Oreochromis niloticus). We know that the expression of $D M R T-1 b(Y)$ in medaka strictly correlates with the Y chromosome and treatment with exogenous estrogen has no effect on its expression (Scholz et al. 2003), and vas-s is predominantly expressed in oogenesis and vas in spermatogenesis in tilapia (Kobayashi et al. 2002), but the functional connection between these three genes remains unclear at this time.

Other researchers have focused on the primary germ cells as directors of sex determination. In gonochoristic species, ovarian tissue in females develops prior to spermatogenic tissue of males. This is hypothesized to be due to the induction of meiosis, resulting in ovarian tissue, or a block to meiosis in the primary germ cells, resulting in testicular tissue (Koubova et al. 2006). Injection studies of medaka embryos with DMY RNA caused a meiotic block compared to control fish (Kobayashi et al. 2004, Nagahama 2006). Recent research suggests a temporal relationship among $D M Y$, Sox9a, and DMRT-1b(Y) (Kobayashi et al. 2004, Nakumoto et al. 2005, Nagahama 2006). While based on RNA and not on functional proteins, this pattern is strongly suggestive of a rudimentary signaling pathway, with $D M Y$ blocking meiosis, Sox $9 a$ regulating testicular tubule development, and DMRT-1b(Y) being important to spermatogenesis itself. To date, this information is only available in a single strain of the medaka.

Due to the interest in the aquaculture of ornamental and food fish species, much has been learnt about the differentiation of sex in fishes (Yamamoto 1969, Donaldson 1996, Devlin \& Nagahama 2002). Sexspecific phenotypic differences are regulated by androgens, principally testosterone and 11-ketotestosterone, in male and 17ß-estradiol in female gonochorists and relevant, respective sex in sequential hermaphrodites. These sex steroids effect their mode of action through intracellular and membrane-bound receptors. Many studies using a suite of androgens or estrogens (in either aquatic exposures, or directly injected or implanted) have demonstrated the importance of these gonadally synthesized sex steroid hormones in sex determination and sexual differentiation. Fish can be readily sex-reversed by exogenous hormone treatment during phenocritical periods. These periods, where the gonad is bipotential, vary from embryonic to juvenile developmental stages. Adult fish can be masculinized or feminized by hormonal treatment, thus supporting the role of sex steroids in the maintenance of gametogenesis as well as the differentiation of secondary sex characteristics, including morphology, coloration, and behavior (Yamamoto 1969, Donaldson 1996, Devlin \& Nagahama 2002). The importance of the relative concentration of these sex steroids has been documented by the manipulation of aromatase, the enzyme that converts androgens to estrogens. Inhibition or stimulation of aromatase can reverse sex as well as alter secondary sex characteristics.

\section{Reproductive biology of the mangrove rivulus}

The mangrove rivulus (Krytolebias marmoratus, synonym Rivulus marmoratus, referred in this paper as rivulus) is an excellent organism to study the mechanisms of sex determination and sexual differentiation because of the uniqueness of its reproductive biology. Among vertebrates, it is the only known self-fertilizing simultaneous hermaphrodite (Harrington 1961). For more information about the life history of the rivulus, see the review paper by Taylor (2000). The cytogenetics of rivulus has been studied, and Sola et al. concluded that the diploid chromosome number is 46 and the chromosomes are homomorphic (Sola et al. 1997). Most rivulus collected from the wild are selfing hermaphrodites, yet in some populations, males are found (only a few males have ever been collected in Florida, yet up to $25 \%$ of fish sampled in Carrie Bow Cay, Belize, are males); (Turner et al. 1992a). In addition to selfing, there is evidence of outcrossing, and the degree and prevalence in wild population is presently being investigated by others (Turner et al., 1990 \#1820, Lin \& Dunson 1995 \#1967, Murphy \& Collier 1996 \#2224, Turner, 1992 \#2987, and Mackiewicz et al. 2006).

As a hermaphroditic species, sex determination is plastic and has a strong environmental influence with temperature being known to affect sex determination (Harrington 1967 \#3612, Harrington 1968 \#3611). In the laboratory, hermaphrodites develop at normal culture temperatures of $25{ }^{\circ} \mathrm{C}$. Primary males (direct development) can be produced when embryos are incubated at $18{ }^{\circ} \mathrm{C}$, although the response is not all or none, i.e. $<70 \%$ develop as males (Harrington 1967). Some hermaphrodites can be induced to develop into secondary males by holding them at $28^{\circ} \mathrm{C}$ (Harrington $1968,1971)$, presumably through degeneration of their ovarian tissue, although this transformation has not been studied systematically (Harrington 1975). Since there is evidence of outcrossing in the Belizean population, mating is presumed to occur between hermaphrodites and males (Turner et al. 1992a,b). Further, Belizean males are about the size of hermaphrodites, hence these are hypothesized to be secondary males; high water temperatures in the tropics may induce the herm $\rightarrow$ secondary male transformation. While hermaphrodites are reported to go through a juvenile female stage prior to ontogeny of testicular tissue (Soto et al. 1992, Cole \& Noakes 1997), no one has ever observed or collected functional, adult females in the field or laboratory until recently. In our lab, $100 \%$ 
juvenile rivulus $\leq 7$ days post-hatching (dph) exposed to ethinyl-estradiol ( $1 \mathrm{ppb}$ until $28 \mathrm{dph}$ ) and raised in untreated water until adulthood (110 dph), developed as females (unpublished data from EFO lab).

Given the importance of sex steroid hormones and their receptors, and the enzyme aromatase in sexual differentiation of fishes, we cloned and sequenced the estrogen receptor (ER $\alpha$ and ER $\beta)$, cloned and partially sequenced ovarian and brain aromatase ( $A r o A$ and $A r o B$ respectively) genes. Next, we compared the expression of $E R \alpha, E R \beta$, AroA, and $A r o B$ genes between the adult hermaphrodite and male rivulus. We hypothesized that there would be differential expression of these genes between these reproductive morphs and that those differences would reflect the presence of ovarian tissue in the hermaphrodite.

\section{Materials and methods}

\section{Fish}

Fourteen adult hermaphrodites and 14 primary males (age 11-12 months) were obtained from a breeding colony of rivulus maintained by EFO. Fish were maintained at $24 \pm 1{ }^{\circ} \mathrm{C}, 16 \mathrm{~h}$ light: $8 \mathrm{~h}$ darkness photoperiod, 15 ppt seawater (reverse osmosis water) plus Instant Ocean sea salts (Aquarium Systems, Inc., Menton, OH, USA) and fed brine shrimp (Artemia salina) nauplii daily ad libitum. Fish were chosen at random, anesthetized with $150 \mathrm{ppm}$ MS-222 buffered with $\mathrm{NaH}_{2} \mathrm{CO}_{3}$ (Sigma), and euthanized by severing the spinal cord immediately posterior to the skull. The brain (including pituitary) and liver were excised and immediately snap-frozen in liquid nitrogen and stored at $-80^{\circ} \mathrm{C}$ for quantitative PCR (QPCR, see below). After a section of the gonad was removed for histology (see below), the remainder was snap-frozen and stored as explained for the brain and liver.

\section{Histological examination of the gonad}

A sample of each gonad was fixed in $10 \%$ neutral buffered formaldehyde, dehydrated in an ethanol series, cleared in CitriSolv (Fisher Scientific, Hampton, NH, USA), and embedded in paraffin. The tissues were sectioned ventrally at $5 \mu \mathrm{m}$ on a rotary microtome and stained with hemotoxylin and eosin-Y (Humason 1997). For each fish, three slides were chosen (from approximate third points in the sample) and stained. The gonadal tissue samples were analyzed for the presence of both ovarian and testicular tissues and only for testicular tissue in the hermaphrodites and male fish respectively (Fig. 1). Only reproductively active fish were acceptable for use in this study. Gonadal tissue was acceptable if oocytes, perinuclear follicles, and
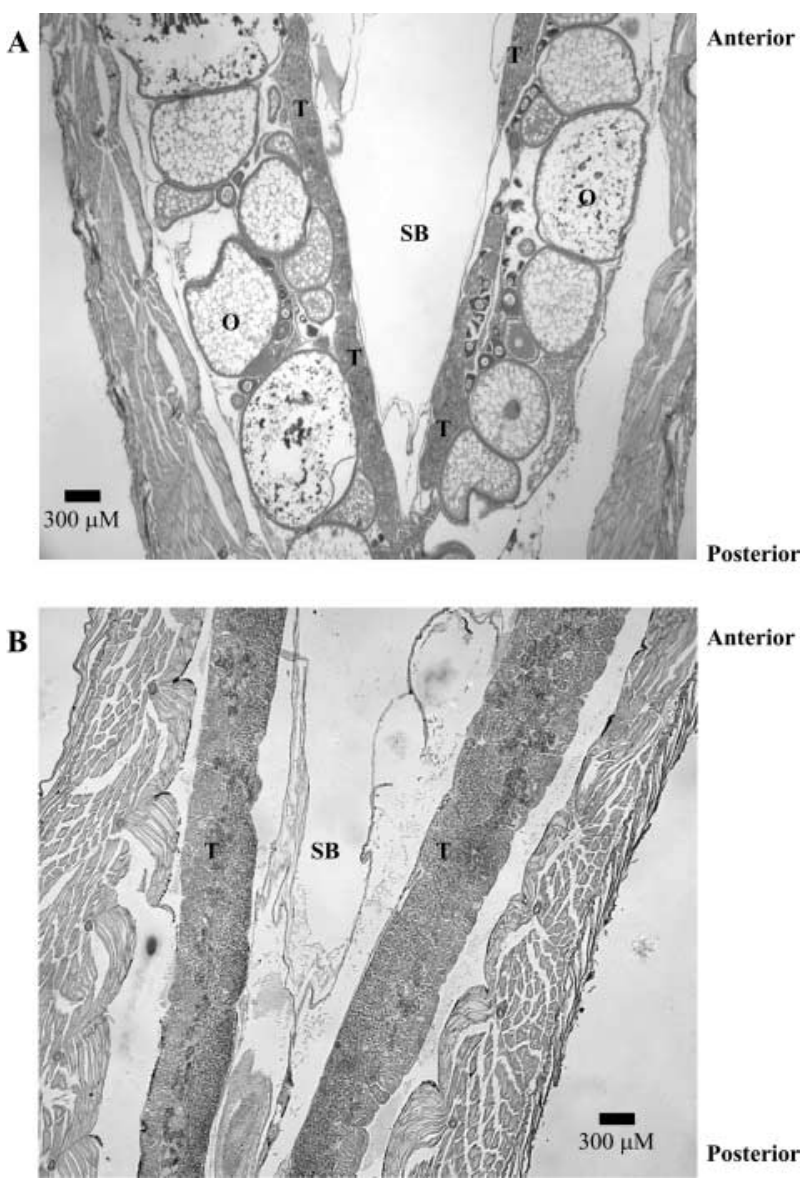

Figure 1 Ventral sections of the rivulus hermaphrodite $(A)$ and male $(B)$ ovarian tissue $(\mathrm{O})$, testicular tissue $(\mathrm{T})$, and swim bladder (SB).

vitellogenic follicles were observed in the ovarian and spermatocytes, spermatatids, spermatozoa were observed in the testicular tissue (modified from (Grier 1981, Wallace \& Selman 1981)).

\section{Cloning and sequencing of $E R \alpha$ and $E R \beta$ genes}

For the ER $\alpha$ and ER $\beta$, two conserved amino acid regions, YHYGVW and NKGME/DQ of fish ER $\alpha$ and ER $\beta$, were selected and their degenerate oligonucleotides were used as primers for PCR. As a template for PCR, first-strand cDNA was synthesized from $1 \mu \mathrm{g}$ of poly (A) RNA isolated from the gonad and the brain. After amplification, the amplified DNA fragment was subcloned with TA-cloning plasmid pGEM-T Easy (Promega), sequenced using a BigDye terminator Cycle Sequencing-kit (PE Biosystems, Foster City, CA, USA) with T7 and SP6 primers, and analyzed on the ABI PRISM 377 automatic sequencer (PE Biosystems). The $5^{\prime}$ - and $3^{\prime}$-ends of the ER cDNA were amplified by rapid amplification of the cDNA end (RACE) using a 
SMART RACE cDNA Amplification kit (BD Biosciences Clontech). For $5^{\prime}$-RACE of ER $\alpha$, two primers were used: $5^{\prime}$-GAGCAGGAGCAGCACCTGTTCAGGAGG-3' ${ }^{\prime}$ for the first round PCR and 5'-TGCTGCTGCGTCTCCTCCCATCATGAC-3 ${ }^{\prime}$ for the second round PCR. For $3^{\prime}$-RACE of $\mathrm{ER} \alpha$, two primers were used: $5^{\prime}$-GCCACCGCCTCTCGCTTCCGCATGCTC-3 ${ }^{\prime}$ for the first round PCR and $5^{\prime}$-ACGGCGCGGCGGTGCAGAACATGCTGG-3' ${ }^{\prime}$ for the second round PCR. For $5^{\prime}$-RACE of ER $\beta$, two primers were used: 5'-GGTCTGCTTATTCGGCCCTGCGAGGAC-3' for the first round PCR and 5'-ACTCGCCTCACCAGCGGGCTCCGATAG- $3^{\prime}$ for the second round PCR. For 3'-RACE of ER $\beta$, two primers were used: $5^{\prime}$-AATATGTGCCTCAGCTCCTCCGAGGGC-3' for the first round PCR and 5'-GACGGACGCTCTGGTGTGGGCCATCG- $3^{\prime}$ for the second round PCR.

\section{Cloning and sequencing of $A r o A$ and $A r o B$ genes}

For the AroA and AroB aromatase genes, two conserved amino acid regions, TACNYYN and RYFQPFG of the fish $A r o A$ and $A r o B$ aromatase genes, were selected and their degenerate oligonucleotides used as primers for PCR. As a template for PCR, first-strand cDNA was synthesized from $1 \mu \mathrm{g}$ poly (A) RNA isolated from the gonad and the brain. After amplification, the amplified DNA fragment was subcloned with TA-cloning plasmid pGEM-T Easy (Promega), sequenced using a BigDye terminator Cycle Sequencing-kit (PE Biosystems) with T7 and SP6 primers, and analyzed on the ABI PRISM 377 automatic sequencer (PE Biosystems). The $5^{\prime}$ - and $3^{\prime}$-ends of the aromatase cDNA were amplified by rapid amplification of the cDNA end (RACE) using a SMART RACE cDNA Amplification kit (BD Biosciences Clontech). For $3^{\prime}$-RACE of AroA, two primers were used: 5'-AGGAGCAGCTGCAGAACCGGGACCTTC-3' for the first round PCR and $5^{\prime}$-AATGCCTCCGCTTCCACCCGGTGG- $3^{\prime}$ for the second round PCR. For 5'-RACE of AroB, two primers were used: 5'-CAGGAGACTGAGGGCGTCCACGTGTCC- $3^{\prime}$ for the first round PCR and 5'-GGCTGTCCAGGTGTTTGGCTGTGGAGC-3' for the second round PCR. For $3^{\prime}$-RACE of AroB, two primers were used: $5^{\prime}$-GCCCCGGACACGCTGTCCATCAGCCTC- $3^{\prime}$ for the first round PCR and $5^{\prime}$-ATGGTGGAGGAGATGAACGCCGCCTTG- $3^{\prime}$ for the second round PCR.

\section{QPCR}

We quantified gene expression using QPCR performed on the ABI Prism 5700 Sequence Detection System with SYBR Green PCR Master Mix according to the manufacturer's instructions (Applied Biosystems, Foster City, CA, USA). Unless noted, all supplies were purchased through Fisher Scientific. The brain, liver, and gonad tissue stored at $-80^{\circ} \mathrm{C}$ were transferred directly to $1 \mathrm{ml}$ cold TRIzol (Invitrogen) and homogenized twice for $30 \mathrm{~s}$ each using a Psychotron NITON, NS 310E (Microtec Co., Ltd, Chiba, Japan). Following homogenization, $200 \mu \mathrm{l}$ of hydrated chloroform was added and the samples were vortexed and incubated at $4{ }^{\circ} \mathrm{C}$ for $30 \mathrm{~min}$. Samples were centrifuged and the aqueous phase was transferred to another tube containing $500 \mu \mathrm{l}$ of isopropanol, vortexed, and incubated at $4{ }^{\circ} \mathrm{C}$ for $30 \mathrm{~min}$. The supernatant was removed and $500 \mu \mathrm{l}$ of $80 \%$ ethanol was added to precipitate total RNA. Total RNA was purified with RNAeasy mini kit following the manufacturer's instructions (Qiagen), quantified using a DU640 spectrophotometer (Beckman Coulter, Fullerton, CA, USA), and adjusted to a final concentration of $0 \cdot 1 \mu \mathrm{g} / \mu \mathrm{l}$. An aliquot of purified RNA was run out on $1 \%$ agarose gel to assure quality.

Total RNA $(1 \cdot 0 \mu \mathrm{g} / \mu \mathrm{l})$ was processed by attaching poly dT-linked primers (Invitrogen) to the poly (A) end of the mRNA following the manufacturer's instructions. cDNA was synthesized with SuperScript II RNAse H reverse transcriptase (Invitrogen) and dNTP mix (Invitrogen) for $10 \mathrm{~min}$ at room temperature, $90 \mathrm{~min}$ at $42^{\circ} \mathrm{C}$, and $10 \mathrm{~min}$ at $70^{\circ} \mathrm{C}$. To run QPCR, SYBR Green PCR Master Mix, forward and reverse primers, and water were combined and gently vortexed. cDNA standards of $2 \mu \mathrm{l}$ (for each gene at 125, 25, 5, and $1 \mu \mathrm{g} / \mu \mathrm{l})$ or samples were combined with $48 \mu \mathrm{l}$ SYBR Green PCR Master Mix, forward and reverse primers, and water. Into each well of a MicroAmp 96-well reaction plate (Applied Biosystems), $15 \mu \mathrm{l}$ of this mixture was pipetted in triplicate for both standards and samples. QPCR cycles were as follows: $50{ }^{\circ} \mathrm{C}$ for $2 \mathrm{~min}, 95^{\circ} \mathrm{C}$ for $10 \mathrm{~min}$, and 40 cycles of $95^{\circ} \mathrm{C}$ for $15 \mathrm{~s}$ and $60^{\circ} \mathrm{C}$ for $1 \mathrm{~min}$. The primers were chosen to amplify short PCR products $(<100 \mathrm{bp})$ with the assistance of Primer Express software (Applied Biosystems) and primer sequences were synthesized by Qiagen (Table 1). Melting curve analysis using ABI Prism 5700 Sequence Detection System software was performed to confirm the primer efficiency.

\section{Data analysis}

All sequences generated were searched for similarity using BLASTN and BLASTP of the National Center of Biotechnology Information. Multiple sequence alignments and construction of unrooted phylogenetic trees were performed using the CLUSTALW (Thompson et al. 1994) and TREEVIEW programs (Page 2000).

Estrogen receptor and aromatase gene expression were normalized by the expression of ribosomal protein L8. Data were checked for homogeneity of variance, transformed where necessary, and retested. Normalized gene expression in the hermaphrodite and the male 
Table 1 Quantitative PCR primer pairs for estrogen receptors, gonadal and brain aromatase, and the ribosomal protein L8 (normalizing) genes

Abbreviation Forward

\section{Gene name}

Estrogen receptor- $\alpha$ Estrogen receptor- $\beta$ Aromatase-ovarian Aromatase-brain Ribosomal protein (normalizing gene)

\section{$E R \alpha$ \\ $E R \beta$ \\ AroA \\ AroB \\ L8}

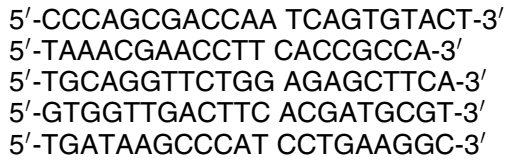

5'-CCCAGCGACCAA TCAGTGTACT-3' 5'-TAAACGAACCTT CACCGCCA-3' 5'-GTGGTTGACTTC ACGATGCGT-3' 5'-TGATAAGCCCAT CCTGAAGGC-3'
Reverse tissues were compared using the $t$-test or where data remained heteroscedastic, using the Mann-Whitney $U$-test (StatView, v 5.0, Cary, NC, USA).

\section{Results}

\section{Cloning and sequencing of $E R \alpha$ and $E R \beta$ genes}

To understand the effects of estrogens on the differentiation of rivulus, we tried to isolate the cDNA clone of ER. Using PCR techniques, partial DNA fragments were amplified from the rivulus gonad RNA. DNA fragments were obtained and sequence analysis showed that the fragments were classified into two kinds of clones, one similar to $\mathrm{ER} \alpha$ and the other to ER $\beta$ (data not shown). Next, using the RACE technique, we were able to clone the full-length rivulus $\mathrm{ER} \alpha$ and $\mathrm{ER} \beta \mathrm{cDNA}$ in the $5^{\prime}$ and $3^{\prime}$ directions, including the ATG start site and the TGA $(\mathrm{ER} \alpha)$, or TAG $(\mathrm{ER} \beta)$ termination signals (Fig. 2; GenBank accession nos $\mathrm{AB} 251458$ and $\mathrm{AB} 251457$ for $\mathrm{ER} \alpha$ and $\mathrm{ER} \beta$ respectively). Rivulus $\mathrm{ER} \alpha$ has a 1743 bp open reading frame with $5^{\prime}$ and $3^{\prime}$ untranslated regions of 358 and $853 \mathrm{bp}$ respectively (Fig. 2, data not shown). The deduced protein is 580 amino acids (aa) with a calculated molecular mass of $62868 \cdot 3$ Da. ER $\beta$ has a 1653 bp open reading frame with $5^{\prime}$ and $3^{\prime}$ untranslated regions of 783 and 779 bp respectively (Fig. 1, data not shown). The deduced protein is 550 aa with a calculated molecular mass of $61268 \cdot 2$ Da.

Amino acid sequences of rivulus $\mathrm{ER} \alpha$ and $\mathrm{ER} \beta$ show an overall homology of $35 \%$. Using the nomenclature of Krust et al. (1986), rivulus $\mathrm{ER} \alpha$ and $\mathrm{ER} \beta$ sequences can be divided into four domains based on their sequence homology to other steroid hormone receptors. Full-length amino acid sequences were used to derive phylogenetic tree data. The two ERs share $5 \%$ homology in the A/B domain, $95.4 \%$ in the $\mathrm{C}$ domain (the DNA-binding domain), $10.9 \%$ in the $\mathrm{D}$ domain, $51.8 \%$ in the $\mathrm{E}$ domain (the ligand-binding domain), and $11 \cdot 1 \%$ in the $\mathrm{F}$ domain (Fig. 2A). Thus, domains $\mathrm{C}$ and $\mathrm{E}$ are highly conserved between rivulus $\mathrm{ER} \alpha$ and $\mathrm{ER} \beta$, whereas $\mathrm{A} / \mathrm{B}, \mathrm{D}$ and $\mathrm{F}$ domains show greater variability. The overall comparison of both rivulus ER amino acid sequences with those of other fishes revealed that they were most similar to the ER sequences of the mummichog (Fundulus heteroclitus) at $78.7 \%$ for $\mathrm{ER} \alpha$ and $83.0 \%$ for $\mathrm{ER} \beta$ and medaka (O. latipes) at $80 \cdot 3 \%$ for $\mathrm{ER} \alpha$ and $76 \cdot 1 \%$ for $\mathrm{ER} \beta$ (data not shown).

Based on the alignment results, phylogenetic analyses were carried out and a phylogenetic tree of $\mathrm{ER} \alpha$ and $\mathrm{ER} \beta$ proteins was constructed using the Neighbor-Joining method (Fig. 2B) (Saitou \& Nei 1987). The unrooted ER distance analysis grouped the $\mathrm{ER} \alpha$ and $\mathrm{ER} \beta$ homologs on separate clades and both rivulus ERs with the corresponding orthologous ER protein of other teleost fish, with high bootstrap supports for both the ERs (Felsenstein 1985). The phylogenetic tree revealed that both $\mathrm{ER} \alpha$ and $\mathrm{ER} \beta$ were most closely related to the mummichog and medaka ERs.

\section{Cloning and sequencing of $A r O A$ and $A r o B$ genes}

To isolate AroA and AroB cDNAs from rivulus, PCRbased amplification techniques were used. DNA fragments were obtained and sequence analysis showed that the fragments were classified into two kinds of clones: one is similar to AroB, and the other to AroA (data not shown). Next, using the RACE technique, we tried to clone the full-length rivulus AroA and AroB. We could obtain the AroB cDNA in the $5^{\prime}$ and $3^{\prime}$ directions including the ATG start site and the TAA termination signal (Fig. 3; GenBank accession no. AB251459). Rivulus AroB has a 1509 bp open reading frame with $5^{\prime}$ and $3^{\prime}$ untranslated regions of 815 and $218 \mathrm{bp}$ respectively (Fig. 3A, data not shown). The deduced protein is 502 aa with a calculated molecular mass of 57 097.33 Da. We could also determine the terminal signal (TGA) and $3^{\prime}$ untranslated region of AroA. Unfortunately, however, we could not determine the ATG start site by $5^{\prime}$ RACE. Partial sequence of AroA has a $1293 \mathrm{bp}$ open reading frame with $3^{\prime}$ untranslated region of $419 \mathrm{bp}$ (GenBank accession no. AB251460, Fig. 3B, data not shown). 
A

ATGTACCCTGAAGAGAGCCGGGGCTCTGGAGGGGTAGCTGCTGTGGACTTCCTAGAGGGG 6

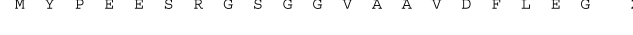
ACGTATGACTATGCTGCCCCCACCCCTGCCCCTACTCCTCTCTACAGCAACTCCACCACT 120 GGGTACTTCTCTGCTCCTCTGGACGCCCACGGACCCCCGTCTAATGGCAGCCTTCAGTCT 180

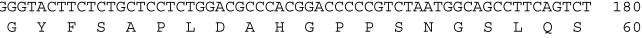
CTAGGAAGTGGGCCAACTAGTCCACTTGTGTTTGTGCCCACCAGTCCAAGGCTCAGCCCC 240

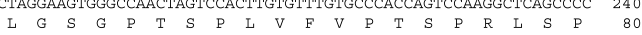
TTPATGCATCCTCCTGGTCACTATCTGGAAACCGCCTCAACACCCGTCTACAGATCCAGC 300

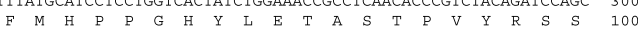
CACCAGCCAGCCTCCAGAGAGGACCAGTGTGACCCCCGTGACGAGGCATGCAGTGTGGGG 360

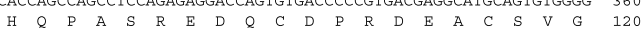
GAGTTAGGAGGTGCAGCCGGCGCCGGGGGGTTTGAGATGGCCAAAGAGACACGTTTCTGT 420

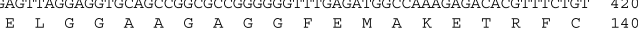
GCCGTGTGCAGCGACTATGCTTCGGGGTACCACTACGGGGTGTGGTCCTGCGAGGGCTGC 480

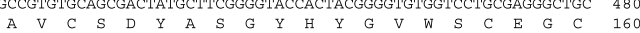
AAGGCCTTCTTCAAGAGGAGCATTCAGGGTCACAATGACTATATGTGCCCAGCGACCAAT 540

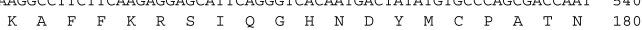
CAGTGTACTATTGACAGGAATCGGAGGAAGAGCTGCCAGGCTTGTCGTCTTAGGAAGTGT 600

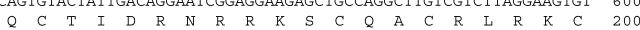
TACGAAGTGGGTATGATGAAAGGAGGTGTGCGCAAAGACCGTGGTCGCGTTTTGCGGCGC 660

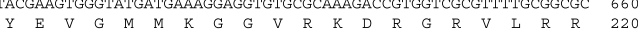
GACAAAAGACGGGGAGGGATTGGAGACAGAGACAAGGTTGCCAAAGGCTTGGAGCACAAA 720

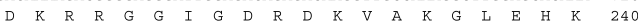
GCAGCAGCCAGTCATGATGGGAGGAGACGCAGCAGCAGCAGCAGCAGCATCGGAGGAGGA 780

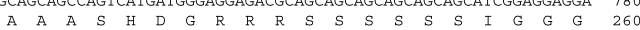
GGAGGAGGAAGATCTTCGTTACTGAATCTTCCTCCTGAACAGGTGCTGCTCCTGCTCCAG 840

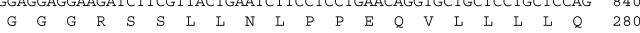
GGCGCCGAGCCACCGATCCTGTGTTCCCGTCAGAAGCTGAGCCGACCCTACACCGAAGTC 900

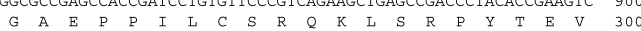
ACCATGATGACCCTGCTCACCAGCATGGCCGACAAGGAGCTGGTCCACATGATCGCCTGG 960

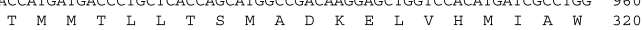
GCCAAGAAGCTTCCAGGTTTCCTGCAGTTGTCTCTCCACGATCAGGTTCTGCTGCTGGAG 1020 $\begin{array}{lllllllllllllllllllll}\text { A } & K & K & \text { K } & \text { P } & \text { G } & \text { F } & \text { L } & Q & \text { L } & \text { S } & \text { L } & \text { H } & \text { D } & \& & \text { V } & \text { L } & \text { L } & \text { L } & \text { E } & 340\end{array}$ AGCTCGTGGCTGGAGATCCTCATGATCGGGCTCATCTGGAGGTCAATCCACTGCCCAGGA 1080

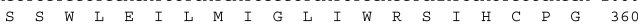
AAGCTCATTTTTGCACAGGACCTCATATTGGACAGGAGCGAGGGCGACTGCGTTGAGGGT 1140

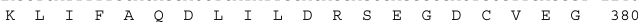
ATGGCGGAGATCTTCGACATGCTGCTGGCCACCGCCTCTCGCTTCCGCATGCTCAAACTC 1200

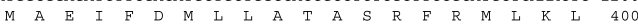
AAACCCGAGGAATTTGTCTGCCTTAAAGCCATCATCCTGCTCAACTCTGGTGCCTTTTCT 1260

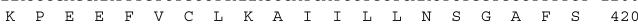
TTCTGCACCGGCACGATGGAGCCCCTTCACGACGGCGCGGCGGTGCAGAACATGCTGGAC 1320 F C T $\quad$ G $T$ T M ACCATCACCGACGCGCTCATACACCACATCAGCCAGTCGGGATACTCGGTTCAGGAGCAG 1380

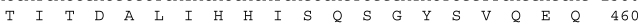
GCGAGACGACAGGCCCAGCTGCTCCTGCTGCTGTCCCACATCAGACACATGAGCAACAAA 1440

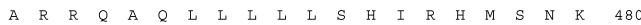
GGCATGGAACATCTGTACAGCATGAAATGCAAGAACAAAGTGCCTCTGTACGACCTGCTG 1500

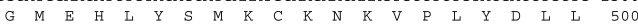
CTGGAGATGCTCGATGCTCACCGCCTCCACCGTCCAGTCAAATCATCTCAGTCCCTGTCC 1560 L E E M L L D A A H CAAGCTGAAAGAGTCGCCCCTTCCTCCTCCTCCTCCTCCTGCTGCGGTGATGGTGGCGGC 1620 Q A $A$ E TCCTCCTCTGCAGGTTGCAGTTCAGGACCTCGAGGCATCAGTGAAAACCCGAGCAGAACC 1680 $\begin{array}{lllllllllllllllllllllll}S & S & \text { S } & \text { A } & G & C & \text { S } & \text { S } & \text { G } & \text { P } & R & \text { G } & \text { I } & \text { S } & \text { E } & \text { N } & \text { P } & \text { S } & \text { R } & \text { T } & 560\end{array}$ CCGTCAGGCCCGAGCGTCCTGCAGTACGGAGGCTCCCGTCCTGACTGCACCAACGCCCTG 1740 P S S G G TGA 1743

Figure 2 Nucleotide sequences of the rivulus $E R \alpha(A)$ and $E R \beta(B)$, and the deduced amino acid sequences.

The deduced amino acid sequences of the rivulus aromatase genes were compared with other fishes (Fig. 4). The overall homology between rivulus AroA and AroB is $57 \cdot 2 \%$. The homologies between AroA in rivulus and those of other fishes, medaka, mummichog,
B

ATGGCCGCGTCACCTCTCCGGAGAAGCATCAGCCGCTCCTGCAGCTCCAAGAGGTGGAC 60

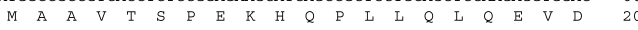
TCCAGTCGGGTCGCCAGTCGCATCCTGTCCCCGGTCCTCAGCTCCTCCCCTGGTCTGTCC 120 CACGAACCCAGCCAGCCCATCTGCATCCCCACTCCGTACACCGACCTCGGCCACGACTTC 180 $\begin{array}{rllllllllllllllllllll}\mathrm{H} & \mathrm{E} & \mathrm{P} & \mathrm{S} & \mathrm{Q} & \mathrm{P} & \mathrm{I} & \mathrm{C} & \mathrm{I} & \mathrm{P} & \mathrm{T} & \mathrm{P} & \mathrm{Y} & \mathrm{T} & \mathrm{D} & \mathrm{L} & \mathrm{G} & \mathrm{H} & \mathrm{D} & \mathrm{F} & 60\end{array}$ CCGCCCATTTCTTTCTACAGCCCGACCATCTTCAGCTACGCCGGTCCGAGCATTTCGGAG 240

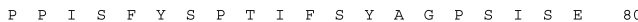
CACCCCTCGGTGCATCAGTCGCTGAGCGCCTCTTTGTTTTGGCCCGGTCACGGACACGTG 300 $\begin{array}{llllllllllllllllllllll}\text { H } & \text { P } & \text { S } & \text { V } & \text { H } & \text { \& } & \text { S } & \text { L } & \text { S } & \text { A } & \text { S } & \text { L } & \text { F } & \text { W } & \text { P } & \text { G } & \text { H } & \text { G } & \text { H } & \text { V } & 100\end{array}$ GGGGGTTCTGTACCCCTGCACCGCTCCCAGACCCGAGCCCAGCAGCACGGTCAGCCAGTC 360

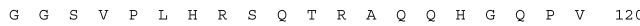
CAGAGTCCGTGGGACAGCGTCTTAACAACCAGTAAGAGTGCGAGGAGGAGCTCCCAGGAG 420 $\begin{array}{llllllllllllllllllllllll}Q & S & P & W & D & S & V & L & T & T & S & K & S & A & R & R & S & S & Q & E & 140\end{array}$ GTCGAGGAGGCCGTGGTGTCGTCCGGCGGGAAGGCCGACCTCCATTACTGCGCCGTGTGT 480 $\begin{array}{llllllllllllllllllllll}\mathrm{V} & \mathrm{E} & \mathrm{E} & \mathrm{A} & \mathrm{V} & \mathrm{V} & \mathrm{S} & \mathrm{S} & \mathrm{G} & \mathrm{G} & \mathrm{K} & \mathrm{A} & \mathrm{D} & \mathrm{L} & \mathrm{H} & \mathrm{Y} & \mathrm{C} & \mathrm{A} & \mathrm{V} & \mathrm{C} & 160\end{array}$ CACGACTACGCCTCGGGGTACCACTACGGCGTCTGGTCCTGCGAGGGCTGCAAGGCCTTC 540 $\begin{array}{lllllllllllllllllllll}\text { H } & D & \text { Y } & \text { A } & S & G & \text { Y } & \text { H } & \text { Y } & G & \text { V } & \text { W } & \text { S } & \text { C } & \text { E } & \text { G } & \text { C } & \text { K } & \text { A } & \text { F } & 180\end{array}$ TTCAAGAGGAGCATCCAAGGACACAACGACTACATCTGCCCGGCAACTAATCAATGCACC 600 $\begin{array}{lllllllllllllllllllll}\mathrm{F} & \mathrm{K} & \mathrm{R} & \mathrm{S} & \mathrm{I} & \mathrm{Q} & \mathrm{G} & \mathrm{H} & \mathrm{N} & \mathrm{D} & \mathrm{Y} & \mathrm{I} & \mathrm{C} & \mathrm{P} & \mathrm{A} & \mathrm{T} & \mathrm{N} & \mathrm{Q} & \mathrm{C} & \mathrm{T} & 200\end{array}$ ATCGACAAAAACCGCCGCAAGAGCTGCCAGGCTTGCCGCCTTCGCAAATGCTATGAAGTT 660 $\begin{array}{lllllllllllllllllllll}I & D & K & N & R & R & K & S & C & Q & A & C & R & \text { L } & R & K & C & Y & E & V & 220\end{array}$ GGCATGACTAAATGTGGTATTCGCAAAGAGCGTGGAAACTATCGGAGCCCGCTGGTGAGG 720 $\begin{array}{lllllllllllllllllllllll}G & M & T & K & C & G & I & R & K & E & R & G & N & Y & R & S & P & L & V & R & 240\end{array}$ CGAGTGACGCGTCTGTCCTCGCAGGGCCGAATAAGCAGACCAAACGTGTTGACTGGACCA 780 $\begin{array}{lllllllllllllllllllll}R & V & T & R & L & S & S & Q & G & R & I & S & R & P & N & V & L & T & G & P & 260\end{array}$ GCGGAGAGTTCGTTAAACGAACCTTCACCGCCATCCATGCCCCCGGGAGCAGCTGATTCAG 840 $\begin{array}{llllllllllllllllllllll}\text { A } & E & S & S & L & N & E & P & S & P & P & S & M & P & P & E & Q & \text { L } & \text { I } & Q & 280\end{array}$ CGAATAATGGAGGCGGAGCCACCAGAGATCTACGTCATGAAGGACATGAAGAGGCCGCTG 900 $\begin{array}{lllllllllllllllllllll}R & I & M & E & A & E & P & P & E & I & Y & V & M & K & D & M & K & R & P & L & 300\end{array}$ ACGGAGGCAGACGTGATGATGTCGCTCACCAATCTGGCTGATAAGGAGCTGGTTCACATG 960 $\begin{array}{lllllllllllllllllllll}\text { T } & \text { E } & \text { A } & \text { D } & \text { V } & \text { M } & \text { M } & \text { S } & \text { L } & \text { T } & \text { N } & \text { L } & \text { A } & \text { D } & \text { K } & \text { E } & \text { L } & \text { V } & \text { H } & \text { M } & 320\end{array}$ ATCAGCTGGGCCAAAAAGATTCCAGGCTTTGTGGAGCTCAGTCTCCTGGACCAGGTCCAT 1020 $\begin{array}{lllllllllllllllllllll}\text { I } & S & \text { W } & \text { A } & \text { K } & \text { K } & \text { I } & \text { P } & \text { G } & \text { F } & \text { V } & \text { E } & \text { L } & \text { S } & \text { L } & \text { L } & \text { D } & Q & \text { V } & \text { H } & 340\end{array}$ CTGTTGGAGTGCTGCTGGCTGGAGGTGCTGATGATGGGACTGATGTGGAGGTCCGTGGAC 1080 $\begin{array}{lllllllllllllllllllll}\text { L } & L & E & C & C & \text { W } & \text { L } & \text { E } & \text { V } & \text { L } & \text { M } & \text { M } & \text { G } & \text { L } & \text { M } & \text { W } & R & \text { S } & \text { V } & \text { D } & 360\end{array}$ CACCCGGGGAAACTCATCTTCTCTCCGGACCTCAGCCTCAGCAGAGAGGAGGGAAGCTGC 1140 $\begin{array}{llllllllllllllllllllll}H & P & G & \text { K } & \text { L } & \text { I } & F & \text { S } & \text { P } & \text { D } & \text { L } & \text { S } & \text { L } & \text { S } & \text { R } & \text { E } & \text { E } & \text { G } & \text { S } & \text { C } & 380\end{array}$ GTCCAGGGCTTCGTGGAGATCTTCGACATGCTGATAGCTGCGACGTCCCGAGTGAGAGAG 1200

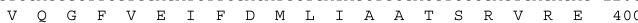
CTCAAACTGAAGAGGGAGGAATACGTCTGCCTCAAGGCCATGATCCTCCTCAACTCCAAT 1260 $\begin{array}{lllllllllllllllllllll}\text { L } & K & \text { L } & \text { K } & \text { R } & \text { E } & \text { E } & \text { Y } & \text { V } & \text { C } & \text { L } & \text { K } & \text { A } & \text { M } & \text { I } & \text { L } & \text { L } & \text { N } & \text { S } & \text { N } & 420\end{array}$ ATGTGCCTCAGCTCCTCCGAGGGCAGCGAGGACCTTCAGAGTCGCTCCAAGCTGCTGCGC 1320 $\begin{array}{lllllllllllllllllllllll}M & C & L & S & S & S & E & G & S & E & D & L & Q & S & R & S & K & L & L & R & 440\end{array}$ CTGCTGGACGCCGTGACGGACGCTCTGGTGTGGGCCATCGCCAAAAGCGGCCTTACCTTC 1380 $\begin{array}{lllllllllllllllllllll}\text { L } & \text { L } & \text { D } & \text { A } & \text { V } & \text { T } & \text { D } & \text { A } & \text { L } & \text { V } & \text { W } & \text { A } & \text { I } & \text { A } & \text { K } & \text { S } & \text { G } & \text { L } & \text { T } & \text { F } & 460\end{array}$ CGGCAGCAGTACACCCGCCTCGCTCACCTGCTCATGCTGCTCTCACACATCCGCCATGTC 1440 $\begin{array}{llllllllllllllllllllll}R & Q & \& & Y & T & R & L & A & H & \text { L } & \text { L } & \text { M } & \text { L } & \text { L } & \text { S } & \text { H } & \text { I } & R & H & \text { V } & 480\end{array}$ AGCAACAAAGGCATGGACCACCTGCACTGCATGAAGATGAAGAACATGGTGCCTTTGTAC 1500 $\begin{array}{llllllllllllllllllllll}S & N & K & G & M & D & H & \text { L } & \text { H } & \text { C } & \text { M } & \text { K } & \text { M } & \text { K } & \text { N } & \text { M } & \text { V } & \text { P } & \text { L } & \text { Y } & 500\end{array}$ GACCTGCTGCTGGAGATGCTGGACGCCCACATCATGCACAGCTCCCGCCTGCCTCACCGC 1560 $\begin{array}{llllllllllllllllllllll}\text { D L } & \text { L } & \text { L } & \text { E } & \text { M } & \text { L } & \text { D } & \text { A } & \text { H } & \text { I } & \text { M } & \text { H } & \text { S } & \text { S } & \text { R } & \text { L } & \text { P } & \text { H } & \text { R } & 520\end{array}$ CCCGCTCAGACGGAGAGTGCCGCCGCCGGACCCTCCAACACCTGGACTCCCAGCAGCGTT 1620 $\begin{array}{lllllllllllllllllllll}\mathrm{P} & \mathrm{A} & \mathrm{Q} & \mathrm{T} & \mathrm{E} & \mathrm{S} & \mathrm{A} & \mathrm{A} & \mathrm{A} & \mathrm{G} & \mathrm{P} & \mathrm{S} & \mathrm{N} & \mathrm{T} & \mathrm{W} & \mathrm{T} & \mathrm{P} & \mathrm{S} & \mathrm{S} & \mathrm{V} & 540\end{array}$ GGAGTGGGAGGTGAAGCCCAGTACTCAGAATAG 1653 G V G G E E A Q roach (Rutilus rutilus), zebrafish (Danio rerio), goldfish (Carassius auratus), and catfish (Ictalurus punctatus) are $83 \cdot 2,83 \cdot 2,63 \cdot 1,62 \cdot 6,59 \cdot 7$, and $59 \cdot 0 \%$ respectively. The homologies between the AroB in rivulus and those of other fishes, medaka, mummichog, roach, zebrafish, 

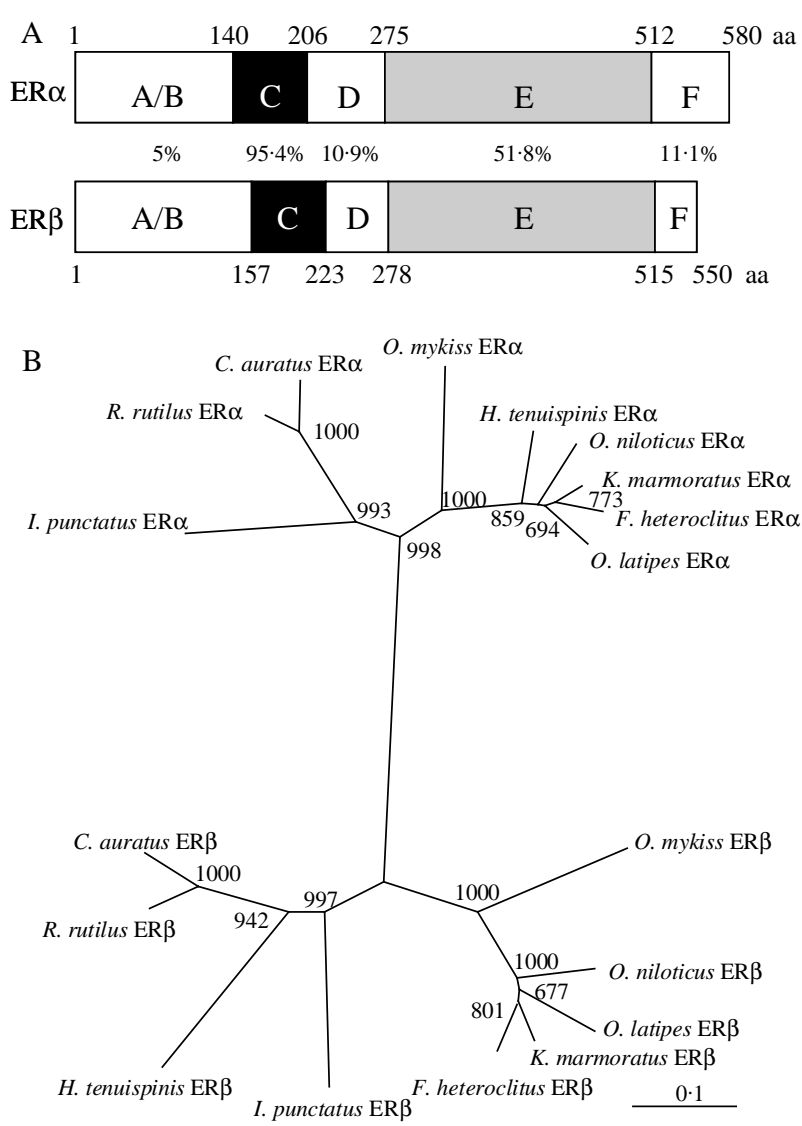

Figure 3 Structure $(A)$ and phylogenetic tree $(B)$ of the rivulus $\mathrm{ER} \alpha$ and $\mathrm{ER} \beta$.

goldfish, and catfish, are $74 \cdot 7,74 \cdot 0,57 \cdot 1,55 \cdot 9,57 \cdot 1$, and $54.4 \%$ respectively. Based on the alignment results, phylogenetic analyses were carried out and a phylogenetic tree of AroA and AroB proteins was constructed using the Neighbor-Joining method (Fig. 4B; Saitou \& Nei 1987). The unrooted aromatase distance analysis grouped the AroA and AroB homologs on separate clades and both rivulus aromatase genes with the corresponding orthologous aromatase protein of other teleost fish, with high bootstrap support for both aromatase genes (Felsenstein 1985). The phylogenetic tree revealed that both AroA and AroB were most closely related to the corresponding medaka and mummichog aromatase genes as with the ER genes (Fig. 5).

\section{QPCR}

For a summary of the expression of $E R \alpha, E R \beta$, AroA, and $A r o B$ genes in the brain, gonad, and liver of hermaphrodites and males, see Table 2. In the liver, ER $\alpha$ expression was $6 \cdot 16 \times$ greater in hermaphrodites compared to males $(P=0 \cdot 0004$, Fig. 6$)$. Similarly, the expression of $E R \beta$ gene was $2 \cdot 21 \times$ greater in hermaphrodites compared to males in the gonad $(P=0 \cdot 0002$, Fig. 6). No difference was observed in either ER $\alpha$ or ER $\beta$ expression in the brains between reproductive morphs.

The expression of AroA gene in the hermaphrodite gonad was $28 \cdot 8 \times$ greater compared to that measured in the male gonad $(P<0 \cdot 0001$, Fig. 7$)$. We measured a $2.73 \times$ increase in $A r o B$ gene expression in the hermaphrodite compared to male brain $(P=0 \cdot 007$, Fig. 7). No differences in AroA or AroB expression were observed between the reproductive morphs in the liver.

\section{Discussion}

We tested the hypothesis that gene expression would differ between rivulus hermaphrodites and males and that expression would reflect the presence of ovarian tissue in the hermaphrodites. In this paper, we show reproductive morph- and tissue-specific differences since hermaphrodites had increased $E R \alpha, E R \beta$, AroA, and $A r o B$ gene expression in the liver, gonad, gonad, and brain respectively, compared to males.

In contrast to mammals, which have two ERs, there are three known ERs in teleost fishes (Hawkins et al. 2000). These include $\mathrm{ER} \alpha$ and two isoforms of $\mathrm{ER} \beta$ : ER $\beta 1$ (ER $\beta$ a or Esr2b) and ER $\beta 2$ (also ER $\beta$ b or Esr2a, and formerly ER $\gamma$; Filby \& Tyler 2005, Hawkins et al. 2005, Pinto et al. 2006). The two ER $\beta$ isoforms arose from a gene duplication following the split between tetrapods and teleosts (Hawkins et al. 2000).

$\mathrm{ER} \alpha$ expression has been measured in a number of species, including Atlantic croaker, zebrafish, sea bream (Sparus auratus), and the fathead minnow (Pimephales promelas) (Menuet et al. 2002, Filby \& Tyler 2005, Hawkins et al. 2005, Pinto et al. 2006). In this study, expression of ER $\alpha$ in rivulus was strongest in the liver and this finding is in agreement with the previous studies. ER $\alpha$ has a strong affinity for estradiol and is upregulated in the liver by estradiol in females and estrogen-exposed male fish, where it induces vitellogenin synthesis (Filby \& Tyler 2005). Given the presence of ovarian tissue, the increased expression of hepatic ER $\alpha$ in the hermaphrodites compared to the males makes sense.

ER $\beta 1$ and ER $\beta 2$ expression has also been characterized in the Atlantic croaker, zebrafish, sea bream, and the fathead minnow (Menuet et al. 2002, Filby \& Tyler 2005, Hawkins et al. 2005, Pinto et al. 2006). In this study, gonadal ER $\beta$ expression was upregulated in the hermaphrodite compared to the male rivulus. Again, these results are consistent with other studies, where $17 \beta$-estradiol synthesized mainly by the ovarian follicular granulosa cells has a stimulatory effect through the 


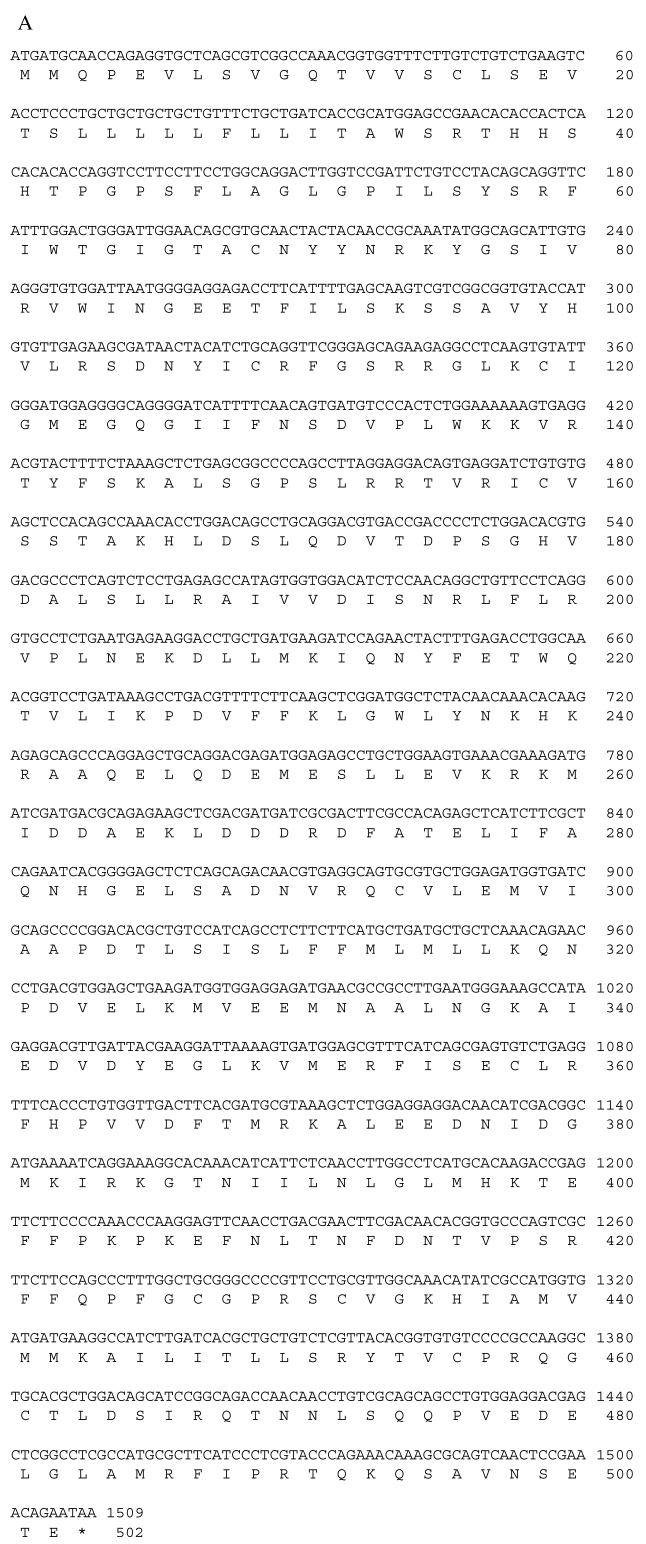

Figure 4 Nucleotide sequences of rivulus brain-type aromatase (A), ovarian-type aromatase (B) and the deduced amino acid sequences.

ER on the ovarian development, oogenesis, and seasonal ovarian recrudescence (Devlin \& Nagahama 2002). Both isoforms of ER are known in the gonads of both sexes in fishes and mammals and there is no general agreement at this time about the relative importance of one isoform over another. All three isoforms of ER are known to be expressed in various brain regions and expression patterns differ in the Atlantic croaker compared to the zebrafish. Using both an analysis of nucleic and amino acid sequences, as well as the immunolocation of $\mathrm{ER} \alpha, \mathrm{ER} \beta 1$, and ER $\beta 2$
B

ACGGCTTGTAATTACTACAACAAGAAGTACGGAGACATGGTGAGAGTGTGGATCAATGGA 60 GAGGAGACCCTGATCCTCAGCAGGGCATCAGCAGTTCATCACGTCCTCAGGAGTGGCAAA 120

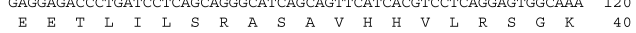
TATACGTCACGCTTCGGGAGCCAGCAGGGACTCCGCTGCCTCGGCATGAATGAGAGAGGC 180 $\begin{array}{llllllllllllllllllllll}Y & T & S & R & F & G & S & Q & Q & G & L & R & C & L & G & M & N & E & R & G & 60\end{array}$ ATCATATTCAACAACAACGTGACTCTGTGGAAAAACATACGCACGTATTTCGCCAAAGCC 240

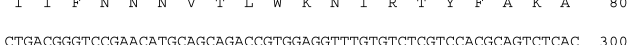
$\begin{array}{lllllllllllllllllllll}\text { L } & T & G & P & N & M & Q & Q & T & V & E & V & C & V & S & S & T & Q & S & H & 100\end{array}$ CTGGACGACCTGGACAGTCTGACTCATGTAGACGTCCTCAGCTTGCTGCGCTGCACCGTG 360 $\begin{array}{cllllllllllllllllllll} & 120 \\ \text { L } & \text { D } & \text { D } & \text { L } & \text { D } & \text { S } & \text { L } & \text { T } & \text { H } & \text { V } & \text { D } & \text { V } & \text { L } & \text { S } & \text { L } & \text { L } & \text { R } & \text { C } & \text { T } & \text { V } & 120\end{array}$ GTGGACATCTCCAACAGGCTCTTCCTGGACGTGCCTCTCGATGAGAAAGAGCTGCTGCTG 420 $\begin{array}{lllllllllllllllllllll}\mathrm{V} & D & I & S & N & R & L & F & L & D & V & P & L & D & E & K & E & L & L & L & 140\end{array}$ AAGATTCAGAAGTACTTTGACACGTGGCAGAGCGTGCTGATCAAACCTGACGTCTACTTC 480 $\begin{array}{lllllllllllllllllllll}K & I & Q & K & Y & F & D & T & W & Q & S & V & \text { L } & \text { I } & K & \text { P } & D & V & Y & F & 160\end{array}$ AGGTTCAGCTGGATTCAGCAGAAACACAAGGCCGCAGCCCAGGAGCTGCAGGACGCCATC 540 $\begin{array}{lllllllllllllllllllll}R & F & S & W & I & Q & Q & K & H & K & A & A & A & Q & E & L & Q & D & A & I & 180\end{array}$ GAAGGCCTCGTTGAGCAGAAGAGGCGGGAAATGGAGCAGGCAGAGAAACTGGACAACATC 600 $\begin{array}{lllllllllllllllllllll}E & G & L & \text { V } & \text { E } & Q & K & R & R & E & M & E & \& & A & E & K & \text { L } & \text { D } & \text { N } & \text { I } & 200\end{array}$ AACTTCGCTGCAGATCTCATCTTTGCACAAAACCACGGCGAGCTGTCCGCCGACAACGTG 660 $\begin{array}{lllllllllllllllllllll}\mathrm{N} & \mathrm{F} & \mathrm{A} & \mathrm{A} & \mathrm{D} & \mathrm{L} & \text { I } & \mathrm{F} & \mathrm{A} & \mathrm{Q} & \mathrm{N} & \mathrm{H} & \mathrm{G} & \mathrm{E} & \mathrm{L} & \mathrm{S} & \mathrm{A} & \mathrm{D} & \mathrm{N} & \mathrm{V} & 220\end{array}$ AGGCAGTGCATGCTGGAGATGGTGATCGCCGCCCCGGACACCCTGTCCATCAGCCTGTTC 720 $\begin{array}{lllllllllllllllllllll}R & \& & C & M & \text { L } & \text { E } & \text { M } & \text { V } & \text { I } & \text { A } & \text { A } & \text { P } & \text { D } & \text { T } & \text { L } & \text { S } & \text { I } & S & \text { L } & F & 240\end{array}$ TTCATGCTGCTGCTCCTCAAACAGAATCCAGATGTGGAGCTGCAGCTGCTGCAGGAGATC 780 $\begin{array}{lllllllllllllllllllll}\text { F } & \text { M } & \text { L } & \text { L } & \text { L } & \text { L } & \text { K } & \text { Q } & \text { N } & \text { P } & \text { D } & \text { V } & \text { E } & \text { L } & \text { Q } & \text { L } & \text { L } & \text { Q } & \text { E } & \text { I } & 260\end{array}$ GACGCTGTCGTAGGTGAGGAGCAGCTGCAGAACCGGGACCTTCAGAAGCTGCAGGTTCTG 840 $\begin{array}{lllllllllllllllllllll}D & A & V & V & G & E & E & Q & \text { L } & Q & N & R & D & L & Q & K & L & Q & V & L & 280\end{array}$ GAGAGCTTCATCAACGAATGCCTCCGCTTCCACCCGGTGGTGGACTTCACCATGCGCCGG 900 $\begin{array}{llllllllllllllllllllll}E & S & F & I & N & E & C & L & R & F & H & P & V & V & D & F & T & M & R & R & 300\end{array}$ GCCCTTTCTGATGACATCATCGACGGCTTCAGGGTACGAAAGGGCACCAACATCATCCTG 960 $\begin{array}{lllllllllllllllllllll}A & L & S & D & D & I & I & D & G & F & R & V & R & K & G & T & N & I & I & L & 320\end{array}$ AACACGGGCCGGATGCACCGGACCGAGTTCTTCCACAGAGCCCAGGAGTTCAGCCTGGAG 1020 AACTTCCAGAAGAATGCCCCTCGCCGCTACTTCCAGCCGTTTGGTTCGGGGCCCCGCGCC 1080 $\begin{array}{lllllllllllllllllllll}N & F & Q & K & N & A & P & R & R & Y & F & Q & P & F & G & S & G & P & R & A & 360\end{array}$ TGCGTTGGCAAACACATCGCCATGGTGATGATGAAGTCCATCCTGGTGACACTGCTGGGT 1140 $\begin{array}{lllllllllllllllllllll}\text { C } & \text { V } & G & \text { K } & \text { H } & \text { I } & \text { A } & \text { M } & \text { V } & \text { M } & \text { M } & \text { K } & \text { S } & \text { I } & \text { L } & \text { V } & \text { T } & \text { L } & \text { L } & \text { G } & 380\end{array}$ CAGTTCTCGGTGTGCCCCCCCCGGGACCTGACCTTGGACTGCCTCCCGCAGACCAACAAC 1200 $\begin{array}{lllllllllllllllllllll}Q & F & S & \text { V } & C & \text { P } & \text { P } & \text { R } & \text { D } & \text { L } & \text { T } & \text { L } & \text { D } & \text { C } & \text { L } & \text { P } & \text { Q } & \text { T } & \text { N } & \text { N } & 400\end{array}$ CTGTCCCAGCAGCCGGTGGAGCACCAGGAGGAGGCAGGAGGCCTCAGCATGAGGTTCTTA 1260 $\begin{array}{lllllllllllllllllllll}L & S & Q & Q & P & V & E & H & Q & E & E & A & G & G & L & S & M & R & F & L & 420\end{array}$ CCCCGACAGAGAGGGAGGTGGCCCTCGCCCTGA 1293

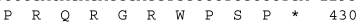
$\begin{array}{lllllllllllllllllllll}N & T & G & R & M & H & R & T & E & F & F & H & R & A & Q & E & F & S & L & E & 340\end{array}$ transcripts to distinct regions of the brain (preoptic area, hypothalamus, and cerebellum) in the Atlantic croaker (Micropogonias undulatus) and distinct yet overlapping brain regions in the zebrafish gives support to the hypothesis that these three forms of ER have specialized functions and enable different regulatory roles of reproduction and behavior (Menuet et al. 2002, Hawkins et al. 2005). In this study, there was no difference in the expression of ER $\beta$ in the brain and we were not able to find evidence of a third ER in rivulus. 

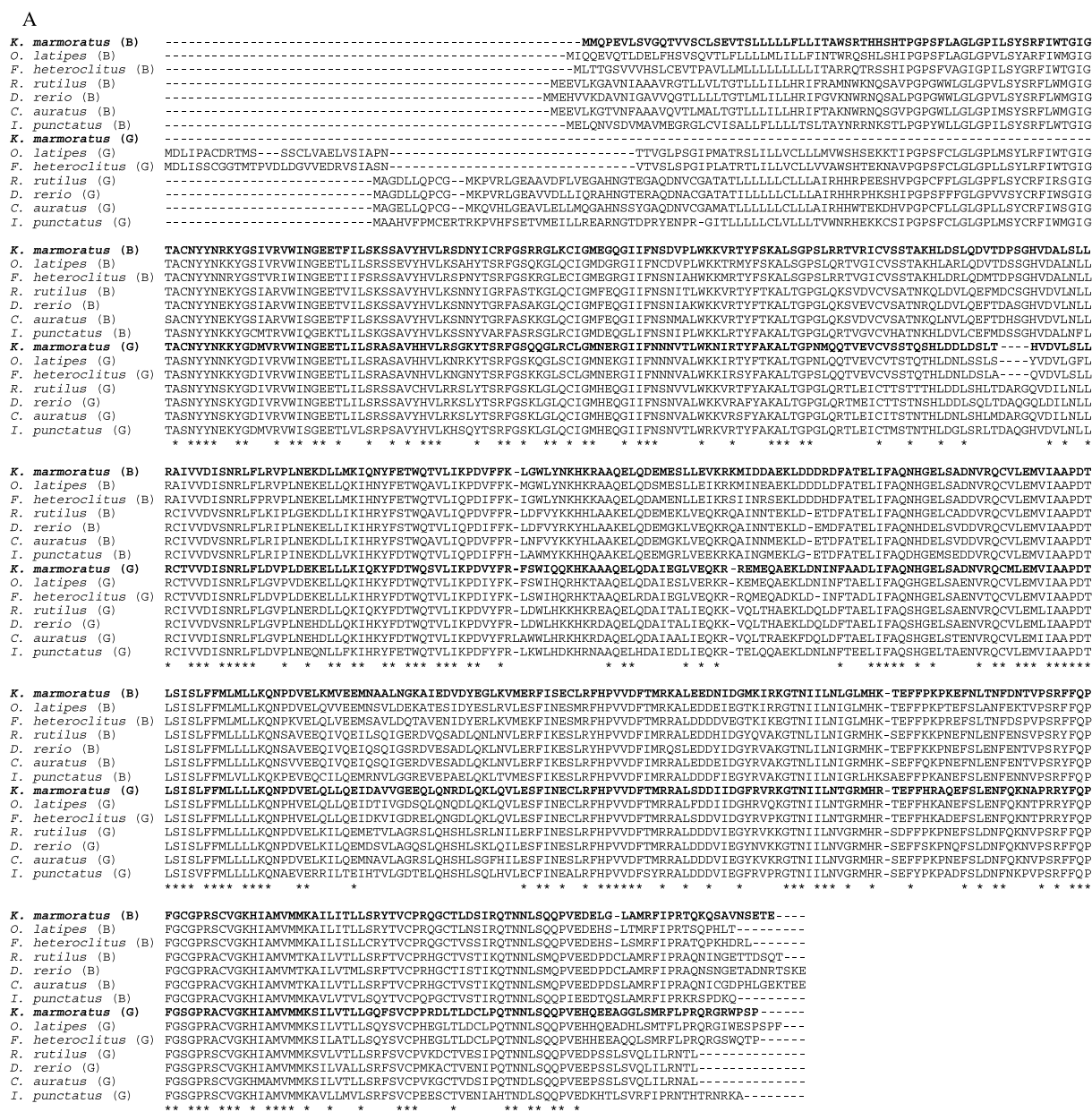

RAIVVDISNRLFPRVPLNEKELLIMKIHNYYETWQTVLIQDDI FFK-I I GWLYNKHKKAAQELQDDMENLLEIKRSI INRSEKLDDDHDFATELIFAQNHGELSADDVRQCVLENVIAAPDT RCIVVDVSNRLFLRIPLNEKDLLIKIHRYFSTWQAVLIQPDVFFR-LNFVYKKYHLAAKELQDEMGKLVEQKRQAINNMEKLD-ETDFATELIFAQNHDELSVDDVRQCVLEMVIAAPDT RCTVVDT SNRLFLGVPVDEKELLOKTHKYFDTWOTVLIKPDTYFK- - SSW I HORHKTAAOELODAIESLVERKR-KEMEOAEKLDNTNFTAELI FAQGHGELSAENVROCVLEMVIAAPDT RCTVVI SNRLFLDVPLDEKELLLKTIRYYFDTWQTVLI IKPDIYFK-LSWIHQRHKTAAQELRDAIEGLVEQKR-RQMEQADKLD - TNFTADLIFAQNHGELSAENVTQCVLENVIAAPDT RCIVDISNRLFLGVPLNERDLLQKIQKYFDTWQTVLIKPDVYFR-LDWLHKKHKREAQELODAITALIEQKK-VQLTHAEKLDQLDFTAELI FAQSHGELSAENVRQCVLEMLIAAPDT RCIVVDT

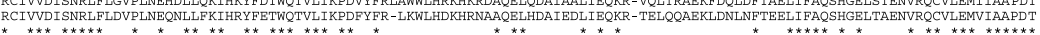

LSISLFFMLMLLKQNPDVELKMVEEMNAALNGKAIEDVDYEGLKVMERFISECLRFHPVVDFTMRKALEEDNIDGMKIRRGTNIILNLGLMHK -TEFFPKPKEFNLTNFDNTVPSRFFQP LSISLFFMLMLLKQNPDVELLVVEEMNSVLDEKATESIDYESLRVLESFINESMRFHPVVDFTMRKALEDDEIEGTKIRRGTNI ILNIGLMHK-TEEFPKPTEFSLANFEKTVPSRF FP

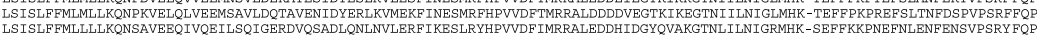

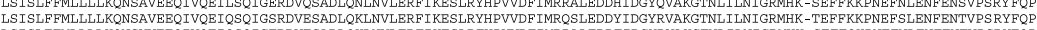
LSISLFFMLLLLKQNSVVEEQIVQEIQSQI GERDVESADLQKLNVLERF IKESLRFHPVVDF IMRRALEDDEIDGYRVAKGTNLILNIGRMHK- SEFFQKPNEFNLENFENTVPSRYFQP

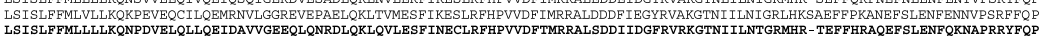

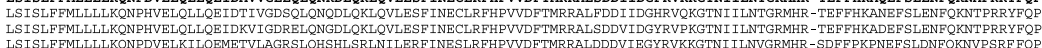
LSISLFFMLLLLKQNPDVELKILQEMETVLAGRSLQHSHLSRLNILERF INESLRFHPVVDFTMRRALDDDVIEGYRVKKGTNIILNVGRMHR - SDFFPKPNEFSLDNFQKNVPSRF FQP LSISLFFMLLLLKQNPDVELKILQEMDSVLAGQSLQHSHLSKLQILESF INESLRFHPVVDFTMRRALDDDVIEGYNVKKGTNI ILNVGRMHR-SEFFSKPNQFSLDNFQKNVPS RFFQP

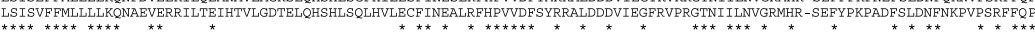

FGCGPRSCVGRHIAMVMMRAILITLLSRYTVCPRQGCTLDSIRQTNNLSQQPVEDELG - LAMRFIPRTQRQSAVNSETE - -

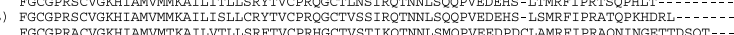
FGCGPRACVGKHIAMVMTKAILVTLLSRFTVCPRHGCTVSTI IRQTNNLSMQPVEEDPDCLAMRFIPRAQNINGETTDSQT--FGCGPRACVGKHTAMYMTKAILVTLLSRFTVCPRHGCTVSTT KOTNNLSMOPVEEDPDSLAMRFIPRAQNICGDPHLGEKTEE FGCGPRACVGKHIAMVMMKAVLVTVLSQYTVCPQPGCTVSTIRQTNNLSRQQPIEEDTQSLAMRFI PRKRSPDKQ--.-.FGSGPRACVGKHIAMVMMKSILVTLLGQFSVCPPRDLTLDCLPQTNNLSQQPVRHQEEAGGLSMRFLPRQRGRWPSP -

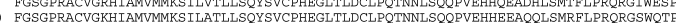
FGSGPRSCVGKHIAMVMMKSVLVTLLSRFSVCPVKDCTVESI PQTNNLSQQPVEDPSSLSVQLILRNTL

FGSGPRSCVGKHMAMVMMKSILVTLLSRFSVCPVKGCTVDSI PQTNDLSQQPVEEPSSLSVQLILRNAL -

B

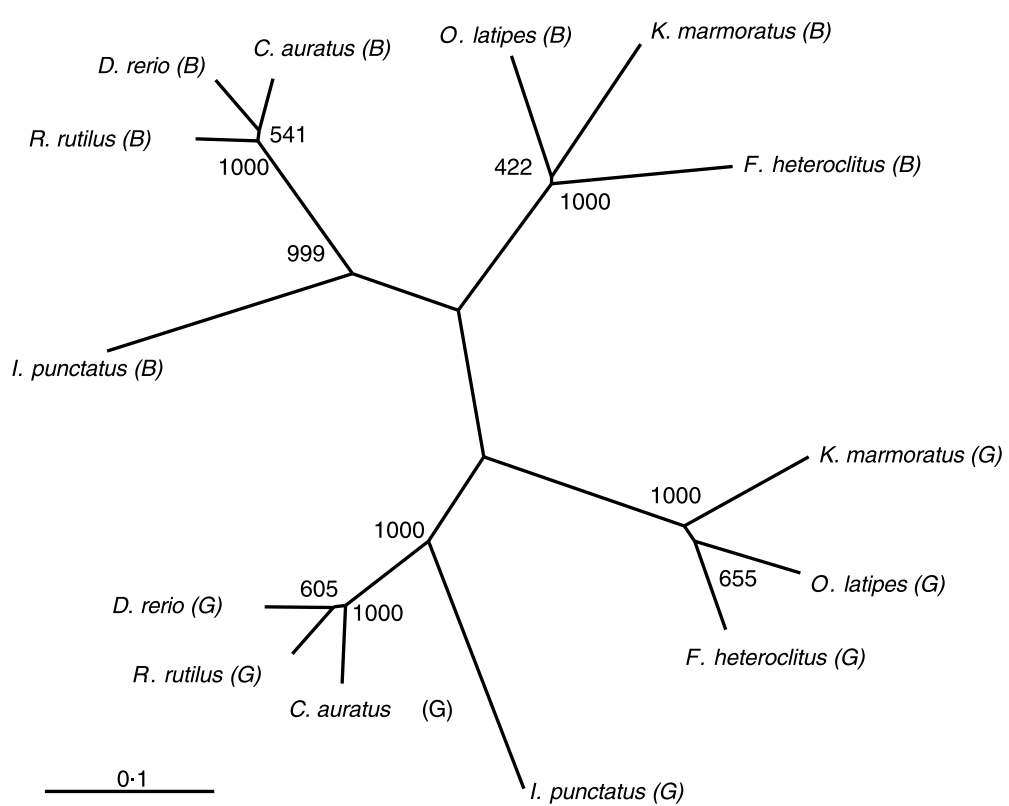

Figure 5 Alignment of the amino acid sequence (A) and phylogenetic tree of rivulus aromatase genes (B), $\operatorname{Aro} A$ and $A r o B$. 
Table 2 Normalized expression of estrogen receptors and ovarian and brain aromatase genes for brain, gonad, and liver

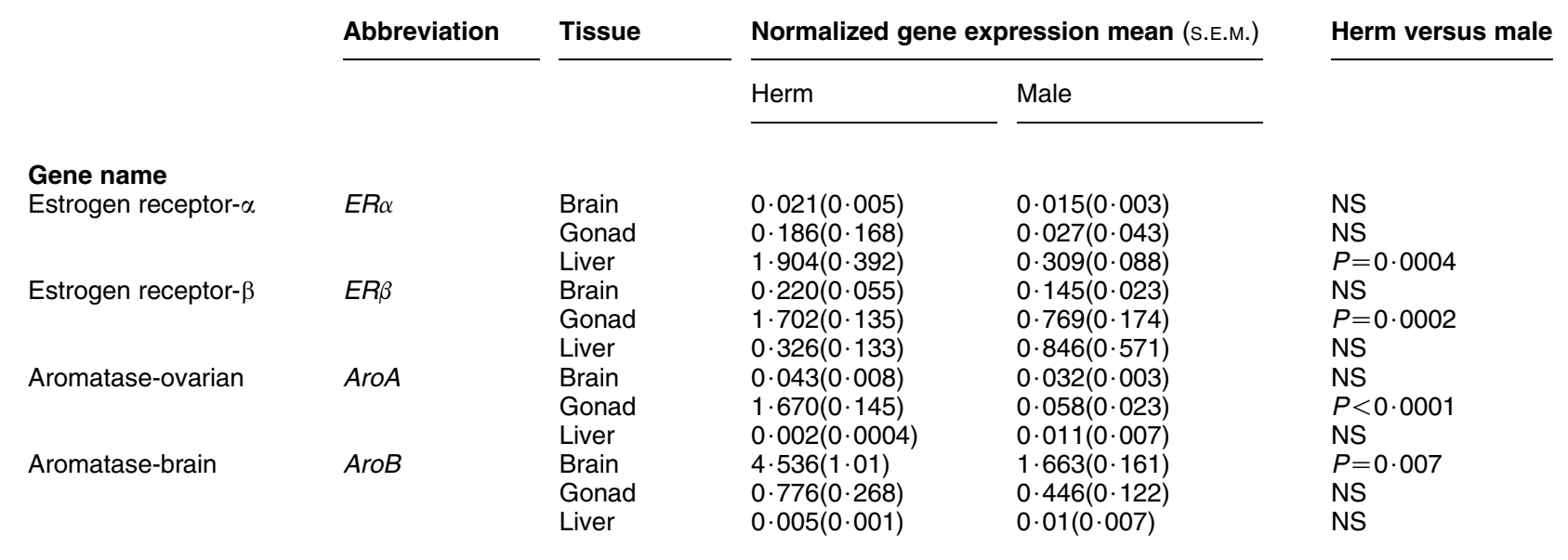

$P$ values as shown and NS, non-significant, values at $P>0 \cdot 05$.

In contrast to most mammals, which have a single aromatase gene, there are two isoforms of aromatase in most teleosts and these are thought to be the result of gene duplication (Simpson et al. 1994, Callard et al. 2001, Pellegrini et al. 2005). As with the ERs, aromatase expression occurs in many tissues including brain, pituitary, gonads, and adipose tissue. However, ovarian aromatase, AroA, is predominantly expressed in the ovary, and brain aromatase, AroB, in the brain. Also unique to teleosts is the magnitude (2-3 orders of magnitude greater than in mammals) of AroB expression and activity in the telencephalon, preoptic area, and hypothalamus of the teleost brain (Callard et al. 1978, Pellegrini et al. 2005). In the brain, furthermore, AroB expression typically exceeds the expression of AroA (Callard et al. 2001).

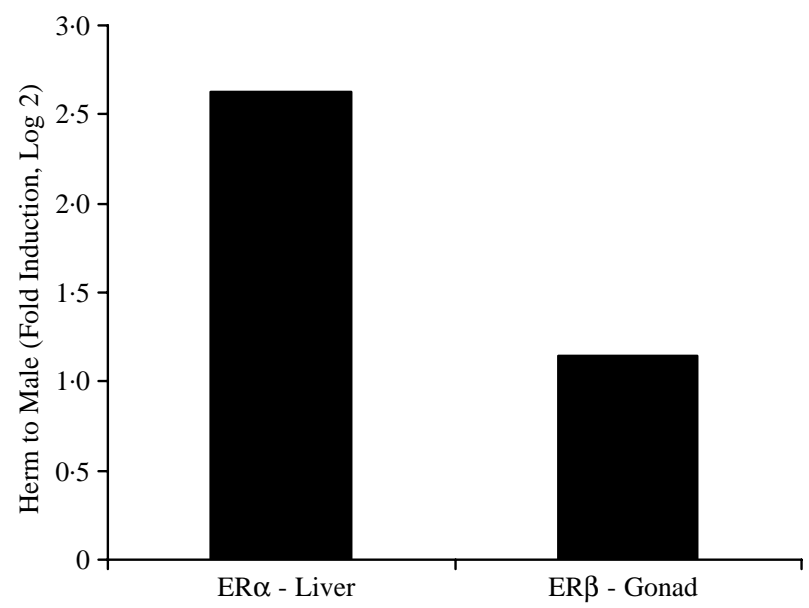

Figure 6 Expression of estrogen receptors, $E R \alpha$ and $E R \beta$, genes in the rivulus brain, gonad, and liver.
In this study, we isolated two aromatase cDNAs, encoding AroA and AroB. AroA cDNA of rivulus was cloned by PCR-based method; it encodes a protein of 430 amino acids with molecular mass of $57 \cdot 1 \mathrm{kDa}$. In addition, the full-length AroB cDNA was isolated from brain RNA using the RACE technique, and the deduced protein was 502 amino acids with a calculated molecular mass of $58 \cdot 6 \mathrm{kDa}$. All fish AroB proteins reported so far have in a range of 488-508 amino acid sequences (Gelinas et al. 1998, Halm et al. 2001, Valle et al. 2002). The amino acid sequence of rivulus AroB has no signal peptide; however, this amino acid sequence is of a membrane protein, which has a transmembrane helix in the $\mathrm{N}$-terminal region (GQTVVSCLSEVTSLLLLLFLLIT). This transmembrane domain is found in wrasse AroB

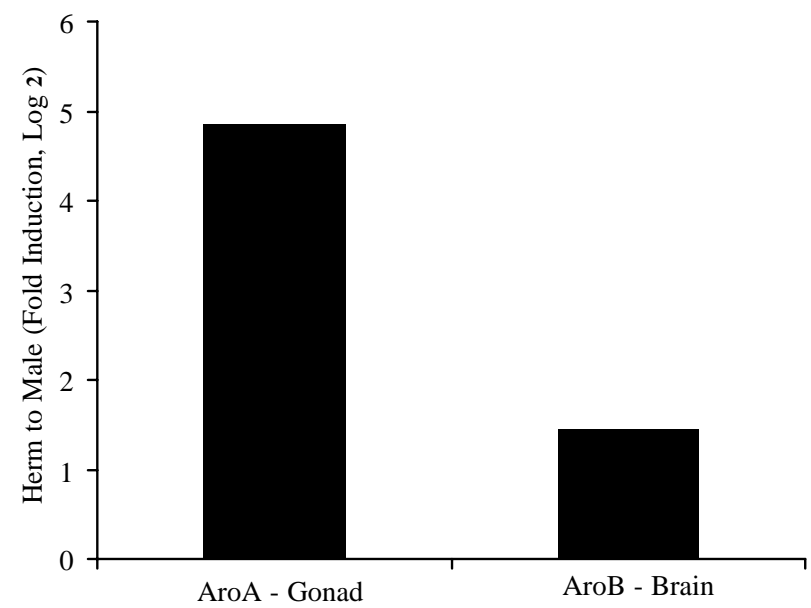

Figure 7 Expression of gonadal and brain aromatase, AroA and $A r o B$, genes in the rivulus brain, gonad, and liver. 
(VTVFLLLMVLLLLFT; Choi et al. 2005). Unfortunately, we could not determine the full sequence of AroA of rivulus. With the information of the full-length sequence, we will be able to better understand the functional structure and evolution of aromatase.

Alignment results of each aromatase subtype showed that the rivulus aromatase shared the highest homology with Cyprinodontiformes aromatases, such as mummichog and medaka. All compared aromatase sequences have higher conservation in functional regions common to both aromatase subtypes. Phylogenetic analysis shows that teleost group separates into two clear clusters, one of them containing the AroA and the other AroB. Rivulus aromatases also belong to each cluster form and this result is consistent with other teleost phylogenetic analysis, such as rainbow trout (Valle et al. 2002) and wrasse (Choi et al. 2005).

In rivulus, we measured greater AroA expression in the gonad of the hermaphrodite compared to the male gonad. These data are in agreement with research on other species and makes sense given the presence of ovarian tissue in the hermaphrodite (Callard et al. 2001). In goldfish and zebrafish, AroA expression was greater in the ovary compared to the testis. Japanese eels (Anguilla japonica) have only one aromatase gene (Jeng et al. 2005). Although making a direct comparison to rivulus is difficult due to this fact, it is interesting to note that the male eels have no measurable aromatase expression in the testis compared to the ovary, where expression is measurable.

The results discussed thus far are in accord with the findings of labs investigating other species. It is comforting to know that, in this initial study of gene expression in rivulus, data from the ERs and AroA genes are consistent with gene expression data reported for other species in the same tissues. Interestingly, the data from this study document the elevated expression of AroB in the hermaphrodite versus male brain.

The functional significance of the dimorphic expression of AroB is unclear at this time. The elevated expression of AroB in hermaphrodites compared with males may be due to different regulatory requirements of an organism with an ovotestis or simply a testis. Most of the hermaphrodites studied in detail are sequential, which are similar to gonochores in that temporally they have functional ovaries that transition into functional testes and vice versa. Prior to these data on rivulus, what we know about the endocrine control of reproductive physiology and/or ethology of simultaneous hermaphroditic fish is found in one published study on the belted sandfish (Serranus subligarius; Cheek et al. 2000). This study was limited to measuring the circulating concentrations of sex steroids during the reproductive season, daily spawning cycles, and contains no information regarding the expression of ERs or aromatase enzyme genes. Nothing is known about the mechanisms regulating simultaneous development of ova and spermatozoa in the same gonad. Sex-specific brain differences in the regulation of gametogenesis are thought to be ultimately modulated by neurotransmitters upstream of GnRHsecreting neurons, i.e., to be controlled by the frequency and amplitude of GnRH release, but there are few published data for this hypothesis in gonochores or sequential hermaphrodites (Parhar et al. 2001, Miranda et al. 2003). Clearly, more research needs to be done to examine the differential expression of AroB and its potential role in the regulation of gametogenesis in the rivulus.

In mammals, aromatase is expressed in the neurons (Balthazart et al. 2003). In teleosts, AroB is known to be synthesized in the radial glial cells of the midshipman (Porichthys notatus), rainbow trout (Oncorhyncus mykiss), and zebrafish (Forlano et al. 2001, Menuet et al. 2002, 2003). Radial glial cells have been shown to play a role in neurogenesis and local synthesis of estradiol has been hypothesized to regulate neurogenesis in adult electric fish (Apteronotus leptorhynchus) and threespine sticklebacks (Gasterosteus aculeatu; Pellegrini et al. 2005). While co-localization of ER and AromB would seem logical, thus far, these functionally related proteins are co-localized to brain/pituitary regions, but have not been found in the same cells (Menuet et al. 2002, 2003). The high levels of AroB in the teleost brain have been hypothesized to enable cell proliferation necessary for requisite sex-specific behaviors and gametogenesis during recrudescence in seasonal reproduction (Pellegrini et al. 2005). It seems unlikely that self-fertilizing rivulus hermaphrodites would have these requirements. In transitioning sequential hermaphrodites, elevated AroB levels may enable cellular proliferation in sex-specific neurons of the new sex (Pellegrini et al. 2005). Secondary male rivulus, which transition from functional selfing hermaphrodites to functional males at $28{ }^{\circ} \mathrm{C}$ might experience an increase in AroB to enable this new brain architecture. The thought that all the hermaphrodites in this experiment were undergoing transition to secondary males is also untenable, given the young age of these fishes and the temperature at which they were housed $\left(24 \pm 1^{\circ} \mathrm{C}\right)$.

One of the weaknesses of the study was the lack of aromatase activity data, i.e., we have no knowledge of the amount of functional enzyme. Future research should examine the aromatase protein catalytic activity together with brain aromatase mRNA quantity to conclude a dimorphism in neuroestrogen synthesis and the potential regulatory role it may play in the reproductive ethology and physiology of the rivulus. 
In conclusion, this is the first study to examine gene expression in the only self-fertilizing vertebrate hermaphrodite known, the mangrove rivulus, $K$. marmoratus. Rivulus is an exciting model for studies on sex determination and sexual differentiation because of the uniqueness of its reproductive biology. This research has laid the groundwork for future investigations of the role of sex steroid hormones in the differentiation of the brain, pituitary, liver, and gonad in the various and intriguing reproductive morphs of this model system.

\section{Acknowledgements}

The authors wish to thank J Beyer, K Bogel, C Lavery, L Chaloux, P Schaughency, and M Mann for their assistance, and A Kanamori and J-S Lee for their cooperation in this project.

\section{Funding}

This research was supported by a National Science Foundation - Japanese Society for the Promotion of Science International Research Fellowship to EFO (US 04015) and to YK and TI Grants in Aid for Scientific Research (17052032) from the Ministry of Education, Science, Sports, and Culture of Japan and Ministry of Environment, Japan. There are no conflicts of interest known that would prejudice the impartiality of the research.

\section{Animal care and use statement}

All research contained in this manuscript was conducted in full compliance with the Florida Atlantic University Institutional Animal Care and Use Committee (permit \#A0601).

\section{References}

Balthazart J, Baillien M, Charlier TD, Cornil C \& Ball GF 2003 Multiple mechanisms control brain aromatase activity at the genomic and nongenomic levels. Journal of Steroid Biochemistry and Molecular Biology 86 367-379.

Callard GV, Petro Z \& Ryan KJ 1978 Phylogenetic distribution of aromatase and other androgen-converting enzymes in the central nervous system. Endocrinology 103 2283-2290.

Callard GV, Tchoudakova AV, Kishida M \& Wood E 2001 Differential tissue distribution, developmental programming, estrogen regulation and promoter characteristics of cyp19 genes in teleost fish. Journal of Steroid Biochemistry and Molecular Biology 79 305-314.

Cheek AO, Thomas P \& Sullivan CV 2000 Sex steroids relative to alternative mating behaviors in the simultaneous hermaphrodite Serranus subligarus (Perciformes: Serranidae). Hormones and Behavior 37 198-211.

Choi JY, Park JG, Jeong HB, Lee YD, Takemura A \& Kim SJ 2005 Molecular cloning of cytochrome $\mathrm{P} 450$ aromatases in the protogynous wrasse, Halichoeres tenuispinis. Comparative Biochemistry and Physiology. Part B, Biochemistry and Molecular Biology 141 49-59.
Cole KS \& Noakes DLG 1997 Gonadal development and sexual allocation in mangrove killifish, Rivulus marmoratus (Pisces: Atherinomorpha). Copeia 596-600.

Damstra T, Barlow S, Bergman A, Kavlock R \& Van Der Kraak J 2002 Global Assessment of the State of the Science of Endocrine Disruptors. Geneva: World Health Organization.

Devlin RH \& Nagahama Y 2002 Sex determination and sex differentiation in fish: an overview of the genetic, physiological, and environmental influences. Aquaculture 208 191-364.

Donaldson EM 1996 Manipulation of reproduction in farmed fish. Animal Reproduction Science 42 381-392.

Felsenstein J 1985 Confidence limits on phylogenies: an approach using the bootstrap. Evolution 39 783-791.

Filby AL \& Tyler CR 2005 Molecular characterization of estrogen receptors $1,2 \mathrm{a}, 2 \mathrm{~b}$, and their tissue and ontogenetic expression profiles in fathead minnow (Pimephales promelas). Biology of Reproduction 73 648-662.

Forlano PM, Deitcher DL, Myers DA \& Bass AH 2001 Anatomical distribution and cellular basis for high levels of aromatase activity in the brain of teleost fish: aromatase enzyme and mRNA expression identify glia as source. Journal of Neuroscience 21 8943-8955.

Gelinas D, Pitoc GA \& Callard GV 1998 Isolation of goldfish brain cytochrome P450 aromatase cDNA: mRNA expression during the seasonal cycle and after steroid treatment. Molecular and Cellular Biochemistry 138 81-93.

Graves JAM 1994 Mammalian sex determining genes. In The Differences Between the Sexes, 1st edn, pp 397-418. Eds RV Short \& E Balaban. Cambridge: Cambridge University Press.

Grier HJ 1981 Cellular organization of the testis and spermatogenesis in fishes. American Zoologist 21 345-357.

Halm S, Rand-Weaver M, Sumpter J \& Tyler CR 2001 Cloning and molecular characterization of an ovarian-derived (brain-like) P450 aromatase cDNA and development of a competitive RT-PCR assay to quantify its expression in the fathead minnow (Pimephales promelas). Fish Physiology and Biochemistry 24 49-62.

Harrington RW Jr 1961 Oviparous hermaphroditic fish with internal self-fertilization. Science 134 1749-1750.

Harrington RW Jr 1967 Environmentally controlled induction of primary male gonorchorists from eggs of the self-fertilizing hermaphroditic fish Rivulus marmoratus Poey. Biological Bulletin 132 174-199.

Harrington RW Jr 1968 Delimitation of the thermolabile phenocritical period of sex determination and differentiation in the ontogeny of the normally hermaphroditic fish Rivulus marmoratus Poey. Physiological Zoology 41 447-460.

Harrington RW Jr 1971 How ecological and genetic factors interact to determine when self-fertilizing hermaphrodites of Rivulus marmoratus change into functional secondary males, with a reappraisal of the modes of intersexuality among fishes. Copeia 3 389-432.

Harrington RW Jr 1975 Sex determination and differentiation among uniparental homozygotes of the hermaphroditic fish Rivulus marmoratus (Cyprinodontidae: Atheriniformes). In Intersexuality in the Animal Kingdom, pp 249-262. Ed R Reinboth. New York: Springer-Verlag.

Hawkins MB, Thorton JW, Crews D, Skipper JK, Dotte A \& Thomas P 2000 Identification of a third distinct estrogen receptor and reclassification of estrogen receptors in teleosts. PNAS $\mathbf{9 7}$ 10751-10756.

Hawkins MB, Godwin J, Crews D \& Thomas P 2005 The distributions of the duplicate oestrogen receptors ER-Ba and ER-Bb in the forebrain of the Atlantic croaker (Micropogonias undulatus) evidence for subfunctionalization after gene duplication. Proceedings of the Royal Society of London, Series B: Biological Sciences 272 633-641.

Humason GL 1997 In Humason's Animal and Tissue Techniques, 5th edn, p 597.Eds JK Presnell \& MP Schreibman. Baltimore: The Johns Hopkins University Press. 
Jeng SR, Dufour S \& Chang CF 2005 Differential expression of neural and gonadal aromatase enzymatic activities in relation to gonadal development in the Japanese eel, Anguilla japonica. Journal of Experimental Zoology A Comparative Experimental Biology 303 802-812.

Kobayashi T, Kajiura-Kobayashi H \& Nagahama Y 2002 Two isoforms of vasa homologs in a teleost fish: their differential expression during germ cell differentiation. Mechanisms of Development 111 167-171.

Kobayashi T, Matsuda M, Kajiura-Kobayashi H, Suzuki A, Saito N, Nakamoto M, Shibata N \& Nagahama Y 2004 Two DM domain genes, $D M Y$ and $D M R T 1$, involved in testicular differentiation and development in the medaka, Oryzias latipes. Developmental Dynamics 231 518-526.

Koubova J, Menke D, Zhou Q, Capel B, Griswold MD \& Page DC 2006 Retinoic acid regulates sex-specific timing of meiotic initiation in mice. PNAS 103 2474-2479.

Krust A, Green S, Argos P, Bumar V, Walter JMB \& Chambon P 1986 The chicken oestrogen receptor sequence: homology with v-erbA and the human oestrogen and glucocorticoid receptors. EMBO Journal 5 891-897.

Lin H \& Dunson WA 1995 An explanation of the high strain diversity of a self fertilizing hermaphroditic fish. Ecology 76 593-605.

Mackiewicz M, Tatarenkov A, Taylor DS, Turner BJ \& Avise JC 2006 Extensive outcrossing and androdioecy in vertebrate species that otherwise reproduces as a self fertilizing hermaphrodite. PNAS 103 9924-9928.

Matsuda M, Nagahama Y, Shinomiya A, Sato T, Matsuda C, Kobayashi T, Morrey CE, Shibata N, Asakawa S, Shimizu N et al. $2002 D M Y$ is a Y-specific DM-domain gene required for male development in the medaka fish. Nature 417 559-563.

Menuet A, Pellegrini E, Anglade I, Blaise O, Laudet V, Kah O \& Pakdel F 2002 Molecular characterization of three estrogen receptor forms in zebrafish: binding characteristics, transactivation properties, and tissue distributions. Biology of Reproduction 66 1881-1892.

Menuet A, Anglade I, Le Guevel R, Pellegrini E, Pakdel F \& Kah O 2003 Distribution of aromatase mRNA and protein in the brain and pituitary of female rainbow trout: comparison with estrogen receptor $\alpha$. Journal of Comparative Neurology 462 180-193.

Miranda LA, Strobl-Mazzulla PH, Strüssmann CA, Parhar I \& Somoza GM 2003 Gonadotropin-releasing hormone neuronal development during the sensitive period of temperature sex determination in the pejerrey fish, Odontesthes bonariensis. General and Comparative Endocrinology 132 444-453.

Murphy WJ \& Collier GE 1996 Phylogenetic relationships within the Aplocheiloid fish genus Rivulus (Cyprinodontiformes, Rivulidae): implications for Caribbean and Central American biogeography. Molecular Biology and Evolution 13 642-649.

Nagahama Y 2006 DMY: the second sex determination gene in vertebrates. Journal of Experimental Zoology A Comparative Experimental Biology 305A 159.

Nagahama Y, Nakamura M, Kitano T \& Tokumoto T 2004 Sexual plasticity in fish: a possible target of endocrine disruptor action. Environmental Sciences: An International Journal of Environmental Physiology and Toxicology 11 73-82.

Nakumoto M, Suzuki A, Matsuda M, Nagahama Y \& Shibata N 2005 Testicular type Sox9 is not involved in sex determination but might be in the development of testicular structures in the medaka, Oryzias latipes. Biochemical and Biophysical Research Communications 333 729-736.

Page RDW 2000 Extracting species trees from complex gene trees: reconciled tree and vertebrate phylogeny. Molecular and Phylogenetic Evolution 14 89-106.
Parhar IS, Tosaki H, Sakuma Y \& Kobayashi M 2001 Sex differences in the brain of goldfish: gonadotropin-releasing hormone and vasotocinergic neurons. Neuroscience 104 1099-1110.

Pellegrini E, Menuet A, Lethimonier C, Adrio F, Gueguen M-M, Tascon C, Anglade I, Pakdel F \& Kah O 2005 Relationships between aromatase and estrogen receptors in the brain of teleost fish. General and Comparative Endocrinology 142 60-66.

Pinto PIS, Passos AL, Martins RS, Power DM \& Canário AVM 2006 Characterization of estrogen receptor $\mathrm{Bb}$ in sea bream (Sparus auratus): phylogeny, ligand-binding, and comparative analysis of expression. General and Comparative Endocrinology 145 197-207.

Saitou N \& Nei M 1987 The neighbor-joining method: a new method for reconstructing phylogenetic trees. Molecular Biology and Evolution 4 406-425.

Scholz S, Rösler S, Schäffer M, Hornung U, Schartl M \& Gutzeit HO 2003 Hormonal induction and stability of monosex populations in the medaka (Oryzias latipes): expression of sex specific marker genes. Biology of Reproduction 69 673-678.

Shapiro DY 1994 Sex change in fishes - how and why?. In The Differences Between the Sexes, 1st edn, pp 105-130. Eds RV Short \& E Balaban. Cambridge: Cambridge University Press.

Simpson ER, Mahendroo MS, Means GD, Kilgore MW, Hinshelwood MM, Graham-Lorence S, Amarneh B, Ito Y, Fisher CR, Michael MD et al. 1994 Aromatase cytochrome P450, the enzyme responsible for estrogen biosynthesis. Endocrine Reviews 15 342-355.

Sola L, Marzovillo M, Rossi A, Gornung E, Bressanello S \& Turner B 1997 Cytogenetic analysis of self-fertilizing fish, Rivulus marmoratus: remarkable chromosomal constancy over a vast geographic range. Genome 40 945-949.

Soto CG, Leatherland JF \& Noakes DLG 1992 Gonadal histology in the self-fertilizing hermaphroditic fish Rivulus marmoratus (pisces, cyprinodontidae). Canadian Journal of Zoology 70 2338-2347.

Taylor DS 2000 Biology and ecology of Rivulus marmoratus: new insights and a review. Florida Scientist 63 242-255.

Thompson J, Higgins D \& Gibson T 1994 Clustal W: improving the sensitivity of progressive multiple sequence alignment through sequence weighting, position-specific gap penalties and weight matrix choice. Nucleic Acids Research 22 4673-4680.

Turner BJ, Davis WP \& Taylor DS 1992a Abundant males in populations of a selfing hermaphroditic fish, Rivulus marmoratus, from some Belize cays. Journal of Fish Biology 40 307-310.

Turner BJ, Elder JF Jr, Laughlin TF, Davis WP \& Taylor DS 1992b Extreme clonal diversity and divergence in populations of a selfing hermaphroditic fish. PNAS 89 10643-10647.

Turner BJ, Elder JF Jr, Laughlin TF \& Davis WP 1990 Genetic variation in clonal vertebrates detected by simple-sequence DNA finger printing. PNAS 87 5653-5657.

Valle LD, Ramina A, Vianello S, Belvedere P \& Columbo L 2002 Cloning of two mRNA variants of brain aromatase cytochrome $\mathrm{P} 450$ in rainbow trout (Oncorhyncus mykiss). Journal of Steroid Biochemistry and Molecular Biology 82 19-32.

Wallace RA \& Selman K 1981 Cellular and dynamic aspects of oocyte growth in teleosts. American Zoologist 21 325-343.

Wilson JD 1994 Translating gonadal sex into phenotypic sex. In The Differences Between the Sexes, 1st edn, pp 203-212. Eds RV Short \& E Balaban. Cambridge: Cambridge University Press.

Yamamoto T 1969 Sex differentiation. In Fish Physiology, p 117.Eds WS Hoar \& DJ Randall. New York: Academic Press.

Received 23 May 2006

Accepted 23 June 2006 